DOE/ER/13045--T1

PURDUE UNIVERSTTY

SCHOOL OF NUCLEAR ENGINEERING

DE93 000403

\title{
Hydrodynamically Induced Dryout and Post Dryout Important to Heavy Water Reactors - A Yearly Progess Report
}

by

M. Ishii, S. T. Revankar, I. Babelli and S. Lele

Thermalhydraulics and Reactor Safety Laboratory

\section{DISCLAIMER}

June 1992

This report was prepared as an account of work sponsored by an agency of the United States Government. Neither the United States Government nor any agency thereof, nor any of their employees, makes any warranty, express or implied, or assumes any legal liability or responsibility for the accuracy, completeness, or usefulness of any information, apparatus, product, or process disclosed, or represents that its use would not infringe privately owned rights. Reference herein to any specific commercial product, process, or service by trade name, trademark, manufacturer, or otherwise does not necessarily constitute or imply its endorsement, recommendation, or favoring by the United States Government or any agency thereof. The views and opinions of authors expressed hereir, do not necessarily state or reflect those of the

Work supported by United States Government or any agency thereof.

\section{U. S. DEPARTMENT OF ENERGY}

- Office of Energy Research 


\section{CONTENTS}

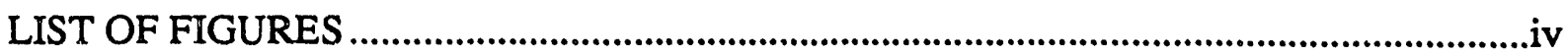

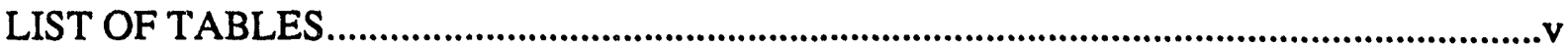

NOMENCLATURE …….................................................................................................

ABSTRACT …

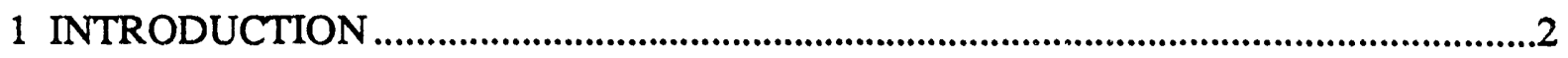

2 CHF UNDER LOW FLOW AND LOW PRESSURE CONDITION.................................4

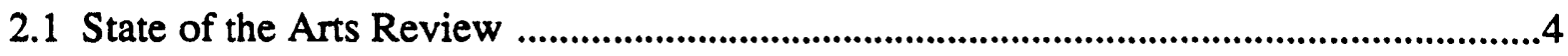

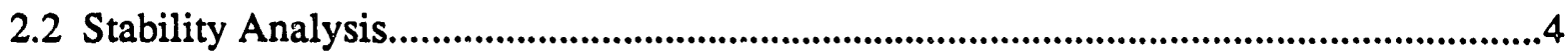

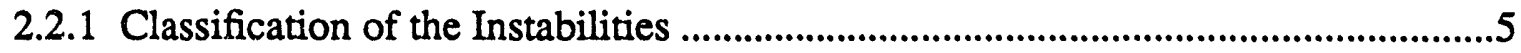

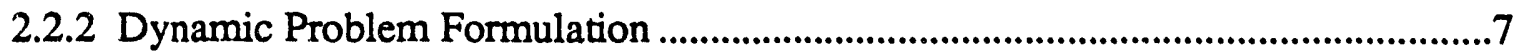

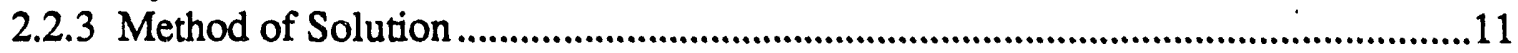

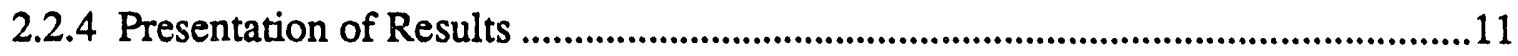

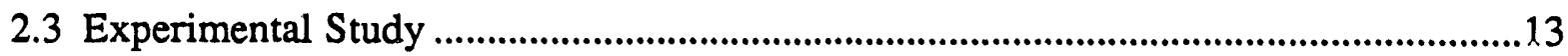

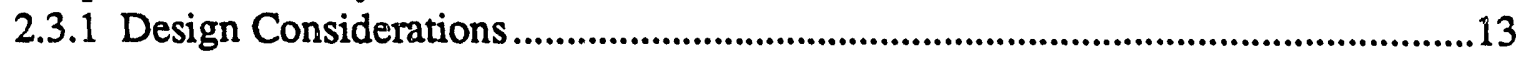

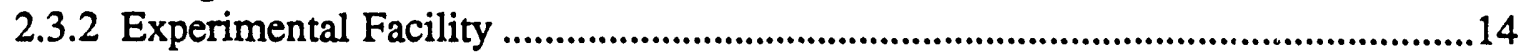

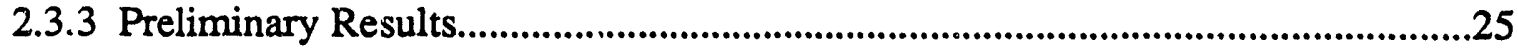

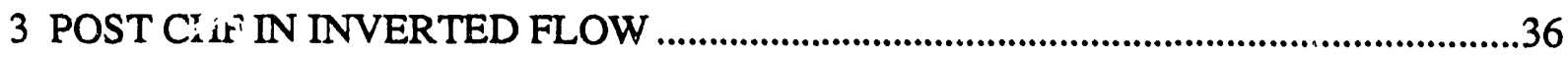

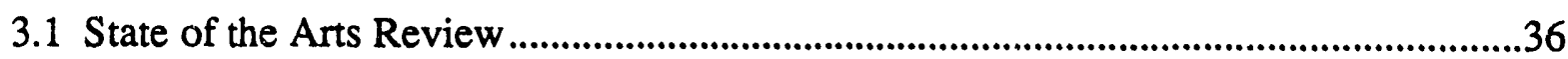

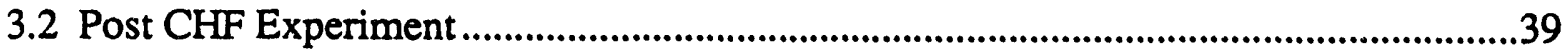

3.2.1 Experimental Facility ...........................................................................................39

3.2.2 Experimental Parameters......................................................................................

3.3 Experimental Observations......................................................................................41

3.3.1 Hydrodynamic Behavior of the Post CHF Flow Field ........................................41

3.3.2 Agitated Liquid Entrainment Mass ....................................................................42

3.3.3 Quench Front Propagation..................................................................................46

3.3.4 Axial Extent of Agitated Flow Regime ...........................................................46

3.3.5 Correlation for Axial Extent of Agitated Region ................................................46

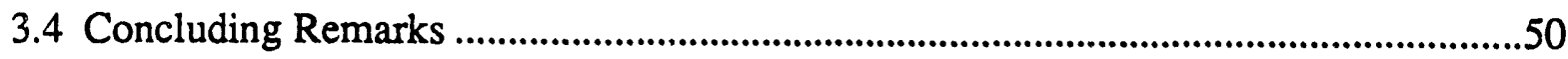

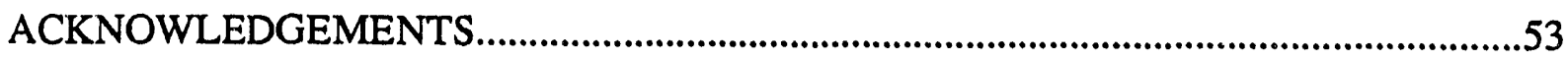

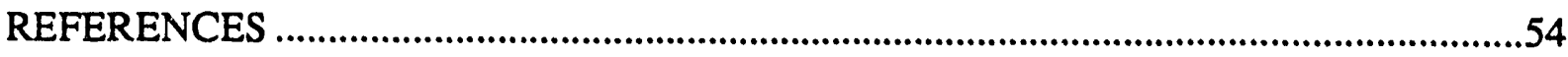




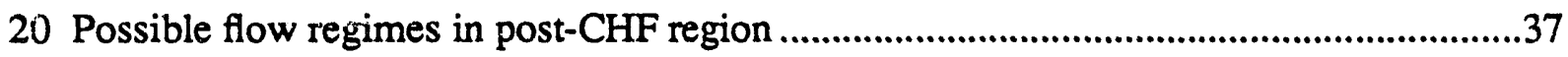

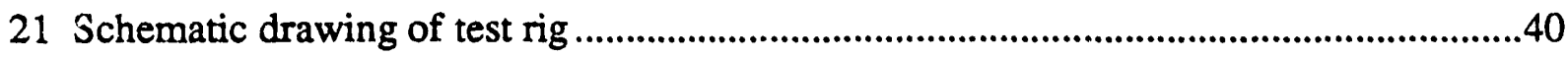

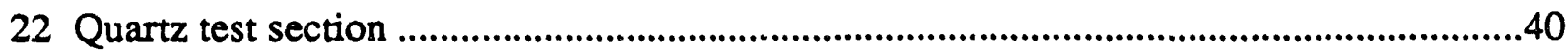

23 Photograph of post-CHF flow illustrating rough wavy regime ....................................43

24 Photograph of post-CHF flow illustrating agitated regime ..........................................44

25 Photograph of post-CHF flow illustrating dispersed droplet/ligament regime ...............45

26 Formation mechanism of agitated mass ....................................................................47

27 Propagation speed of quench front .........................................................................48

28 Axial extent of agitated regime - pre-CHF bubbly flow .......................................48

29 Axial extent of agitated regime - pre-CHF slug flow ................................................49

30 Axial extent of agitated regime - pre-CHF annular flow ........................................49

31 Axial extent of agitated flow regime scaled by two-phase capillary number ..................51

\section{LIST OF TABLES}

1 Parameters for prototype (Fuel-Target) and model ...............................................16

2 Parameters for prototype (Fuel-Fuel) and model ....................................................17 


\section{NOMENCLATURE}

\begin{tabular}{|c|c|}
\hline A & channel cross sectional area \\
\hline $\mathrm{Ca}$ & capillary number \\
\hline D & hydraulic diameter, jet nozzle diameter \\
\hline$f$ & friction factor \\
\hline $\mathrm{g}$ & geavitational acceleration \\
\hline $\mathrm{i}$ & enthalpy \\
\hline I & inertia \\
\hline j & volumetric flux \\
\hline k & loss coefficient \\
\hline 1 & distance \\
\hline $\mathrm{L}$ & distance, axial extent of flow regime \\
\hline $\mathbf{N}$ & number \\
\hline $\mathrm{p}, \mathrm{P}$ & pressure \\
\hline$q^{\prime \prime}$ & heat flux \\
\hline$t$ & time \\
\hline$v$ & velocity \\
\hline$v_{g j}$ & drift velocity \\
\hline w & mass flux \\
\hline $\mathbf{x}$ & quality \\
\hline$z$ & length variable \\
\hline
\end{tabular}




\section{Greek Symbols}

$\alpha$

void fraction of gas phase

$\delta(\mathrm{x}) \quad$ perturbation on $\mathrm{x}$

$\Delta \mathrm{p} \quad$ pressure drop

$\Delta \mathrm{i}_{\mathrm{fg}} \quad$ latent heat of evaporation

$\eta \quad$ heated perimeter

$\varepsilon \quad$ surface roughness

$\lambda \quad$ length at boiling point

$\mu \quad$ viscocity

p density

$\sigma \quad$ surface tension

\section{Subscripts}

c

value at orifice throat

e

at exit

f

liquid phase

g

gas phase

i

value at ithe section

jet nozzle

m mixture

0

at entrance condition

pch phase change

$\operatorname{Re} \quad$ Reynolds 
at saturation

Sub subcooling

Symbols

- average

viii 


\title{
HYDRODYNAMICALLY INDUCED DRYOUT AND POST DRYOUT IMPORTANT TO HEAVY WATER REACTORS- A Yearly Progess Report
}

by

\author{
M. Ishii, S. T. Revankar, I. Babelli and S. Lele
}

\begin{abstract}
Recently, the safety of low pressure liquid cooled nuclear reactors has become a very important issue with reference to the operation of the heavy water reactors at Savannah River Plant. Under accident conditions such as loss-of-flow or loss-of-coolant, these reactors typically encounter unstable two-phase flow which may lead to the occurrence of dryout and subsequent fuel failure. An anlytical study using the one-dimensional drift flux model was carried out to investigate the two-phase flow instability for Westinghouse Savannah River Site reactor. The analysis indicates that the first and higher order instabilities exist in the possible transient operational conditions. The instabilities are encountered at higher heat fluxes or lower flow rates. The subcooling has a stabilizing effect except at very low subcooling. An experimental loop has been designed and constructed to study the CHF induced by various flow instabilities. Details of this test loop are presented. Initial test results have been presented.

The two-phase flow regimes and hydrodynamic behaviors in the post dryout region have been studied under propagating rewetting conditions. The effect of subcooling and inlet velocity on flow transition as well as on the quench front propagation was investigated. The test liquic was Freon 113 which was introduced into the bottom of the quartz test section whose walls were maintained well above the film boiling temperature of the test liquid, via a transparent heat transfer fluid. The flow regimes observed down stream of the upward moving quench front were the rough wavy, the agitated, and the dispersed droplet/ligaments. A correlation for the flow regime transition between the inverted annular and the dispersed droplet/ligament flow patterns was developed. The correlation showed a marked dependence on the void fraction at the CHF location and hence on the flow regime encountered in the pre-CHF region.
\end{abstract}




\section{INTRODUCTION}

The phenomena of critical heat flux (CHF) results in a build up of an insulating vapor layer on the surface of the heater. This leads to abrupt reduction in heat transfer rate and rise in the heater surface temperature, that may lead to material failure of the heater. Generally the CHF mechanism under flow boiling conditions can be classified in to two categories depending on the vapor quality. At low vapor quality, the CHF is noted by a transition from nucleate boiling to film boiling. This is also called departure from nucleate boiling (DNB). This typically occurs at high pressure and/or high coolant mass velocities. On the otherhand at high vapor quality the CHF occurs mainly by dryout process where prior to reaching CHF the heater surface is covered by thin layer of liquid, while the bulk of the coolant flow consists of mixture of vapor and entrained liquid droplets. As the heat flux increases the thickness of the liquid layer decreases due to evaporation. With enough heat flux the surface dries out causing abrupt rise in heater surface temprature. Typically this dryout C.HF occurs in constrained geometries and at saturated or near saturated flow conditions. The values of dryout CHF are lower than the DNB type CHF which occur at low vapor qualities. The dryout $\mathrm{CHF}$ is very important at low pressure and low flow conditions. Because at these conditions various flow instabilities due to boiling occur and lead to premature CHF situations $[1,2]$.

Recently, the safety of low pressure liquid cooled nuclear reactors has become a very important issue as examplified by the heavy water reactors at Savannah River Plant (SRP). Because the design of the SRP reactors differs significantly from commercial reactors, the safety analysis methodology developed for the commercial reactors can not be applied directly to the SRP reactors. Under accident conditions such as loss-of-flow or loss-ofcoolant, these reactors typically encounter unstable two-phase flow which may lead to the occurrence of dryout and subsequent fuel failures. These hydrodynamically induced CHF phenomena under forced convection at low pressure (large density ratio) and low flow conditions are quite different from those well understood CHF phenomena [3-5].

Beyond CHF, the direct liquid/solid contact can not be sustained and this leads to much higher temperatures for the heaters/fuel assemblies. However, the ultimate failure of the fuel assemblies depends on the post dryout heat transfer and duration of dryout. There are recent experimental indications that the post dryout heat transfer can be relatively high at low qualities [6-8]. This may delay the timing of the burnout or mitigate the fuel failure under certain conditions. It should be noted that the hydrodynamically induced CHF are not limited to the downward flow systems.

Inspite of the importance of the coolability limit imposed by the CHF and post CHF heat transfer under low flow and low pressure conditions, the main emphases of reactor safety analyses both for water and liquid-metal cooled reactors have been directed to more drastic accident conditions where natural convection boiling or low flow hydrodynamically induced 
CHF are of little importance. It can be recognized that the low flow CHF phenomena is important in several key areas:

1) Safety analysis of existing and new production reactors or research reactors

2) Safety analysis of liquid metal cooled reactors

3) Safety analysis of decay heat removal by natural convection boiling in conventional light waiter reactors.

Only recently, the importance of the CHF phenomena at low flow and low pressure has been recognized. However, the state of the art indicates that a clear understanding of these phenomen $a$ has not been attained yet. Well designed experimental studies to generate benchmark data as well as careful mechanistic modeling are needed to develop reliable predictive method for those phenomena. In relation to isotope production reactors, the post dryout heat transfer and two-phase flow are very important due to occurrences of the premature dryout caused by the hydrodynamic anstabilities.

The present investigation is aimed at developing a clear understandings and reliable predictive methods for the low flow CHF phenomena and post dryout heat transfer at low pressures. A particular focus is on the hydrodynamically induced dryout and subsequent post dryout phenomena at down flow conditions. 


\section{CHF UNDER LOW FLOW AND LOW PRESSURE CONDITIONS}

\subsection{State of the Arts Review}

Barnard et al. [9] investigated dryout flow rate for an upward flow of Freon-113 in a vertical tube. They classified the burnout mechanisms into five types. When the flow passages are substantially filled with liquid, the burnout will occur due to the vapor production by boiling which prevents liquid from reaching the heated surface. This is the well-known pool boiling burnout. Flooding limited burnout occurs at zero net flow through the flow passage when the vapor flow prevents a sufficient downward flow of liquid [10]. When the flow rate through the flow passage is not zero, but very low, all liquid entering into the passage from the bottom will be evaporated and the vapor flow will prevent liquid flowing down from the top. In this case, the dryout occurs when the vapor quality approaches $100 \%$. This is called a circulation limited burnout. For higher flow rates, a substantial amount of the liquid will be entrained by the vapor flow, which causes dryout at vapor qualities less than $100 \%$. This is so called entrainment burnout. The last two types have often been referred to as a basic mechanism of burnout in annular two-phase flow [11]. However, the observations by Mishima and Ishii [3,4] indicated the possibility of burnout caused by the flow regime transition from churn-turbulent to annular flow. This type of burnout occurred over the same range of mass velocity as circulation limited burnout. At present boundary between these different types of burnout cannot be predicted with high accuracy.

The effects of the flow instabilities $[12,13]$, flow regime transition and counter current flow limitations on the CHF are not fully understood. This is particularly true for an initially downward flow system. Ishii and Fauske[14] analyzed a loss-of-piping integrity accident for a loop type LMFBR. The result showed that the rapid flow decay toward a flow reversal lead to the two-phase excursion and subsequent premature dryoit. Furthermore it was pointed out that the effect of the hysteresis for the flow excursion was significant. Thus the system could only recover from the dryout condition at a heat flux which was much lower than the CHF point.

\subsection{Stability Analysis}

Here the stability analysis for Westinghouse Savannah River Site Reactor has been carried out. The problem formulation was based on time and area averaged one dimensional drift flux model, with the necessary constitutive equations. A characteristic equation was obtained by analytically integrating the set of conservative equations for transient conditions using the small perturbation method. The characteristic equation was solved for the stability interms of the operating conditions. Using this characteristic equation stability boundary will be obtained and represented in the stability plane of the phase change number and subcooling 
the stability of the system were studied and presented in graphical forms.

\subsubsection{Classification of Instabilities}

Two phase flow instabilities can be conveniently classified (Boure' et al [12]) into those instability mechanisms which can be explained in terms of steady state laws (static instabilities), and those which can be explained in terms of transient conservation equations (dynamic instabilities). Several examples of each type of instability mode are given below.

a) Static Instabilities :

1. Excursive (Ledinegg) instabilities

2. Flow regime relaxation instabilities

3. Nucleation instabilities

b) Dynamic Instabilities :

1. Density wave oscillations

2. Pressure drop oscillations

3. Flow regime excited instabilities

4. Acoustic instabilities

5. Condensation induced instabilities

The most important instability modes of practical concern are the excursive and density wave modes. Flow regime relaxation instability is caused by the different pressure drop characteristics of different flow regimes. Flow fluctuations can result in flow regime transition, causing pressure drop fluctuations which cause flow fluctuations : this shows that the instability can be cyclic. Nucleation instabilities include bumping and geysering phenomena, and are characterized by periodic relaxation of the metastable condition that builds up due to insufficient nucleation sites. Liquid superheat can build up until the existing nucleation sites are activated, then rapid boiling and expulsion of two phase mixture may occur.

If a system with a compressible volume has a pressure drop curve with a negative slope, periodic flow excursions may occur, resulting into pressure drop fluctuations. The reason for periodic flow excursion is that the compressible volume causes the flow to divert in such a way as to compensate the pressure drop fluctuations caused by flow perturbation. The liquid inertia causes the flow to fluctuate back and forth, giving rise to pressure drop oscillations. Flow regime excited instabilities can occur when a particular flow pattern, normally slug flow, induces a periodic disturbance in the system operating state. If the frequency of the disturbance is close to the natural frequency of the two phase system, a resonance can occur.

Acoustic instabilities may occur due to the proper combination of system geometry and sonic speed. Similar to single phase compressible fluid flow, organ pipe type standing waves 
can be set up by a pressure pulse propagating at the local speed of sound through two phase mixtures flowing in a conduit. Condensation induced instabilities can lead to large waterhammer type loads. A typical example is the so called chugging phenomena observed in the vent pipes of steam relief valves submerged into a liquid pool. High velocity steam in the form of a jet within the pool collapses due to condensation, causing a liquid slug to surge up in the discharge line. Steam can heat up its interface to saturation, allowing the discharging steam pressure to increase, such that the slug is blown back into the pool. A cyclic process of this kind is associated with large inertial loads transmitted to the walls of the vessel containing the liquid pool

\section{Excursive Instabilities}

Excursive instabilities are nonperiodic flow excursions. Instabilities of this type often caused problems in the early low pressure fossil boilers, since flow excursions can lead to burnout of the boiler tubes. Ledinegg [15] was the first to analyze the instability successfully, and hence the instability is also referred as Ledinegg instability. To understand the instability, consider the transient momentum equation for a boiling loop written in the form

$$
\mathrm{I} \frac{\mathrm{dw}}{\mathrm{dt}}=\left[\Delta \mathrm{p}_{\text {pump }}-\Delta \mathrm{p}_{\text {loop }}\right]
$$

where $\delta \mathrm{p}_{\text {loop }}$ is the loop pressure drop, $\delta \mathrm{p}_{\mathrm{pump}}$ is the pressure rise due to the pump, and the loop inertia I, is given by

$$
I=\sum_{i=1}^{N} \frac{L_{i}}{A_{i}}
$$

where $L_{i}$ and $A_{i}$ are the duct length and flow area in section $i$.

Consider a small flow perturbation about the steady state

$$
w(t)=w_{0}+\delta w(t)
$$

Equations (1) and (3) imply

$$
\mathrm{I} \frac{\mathrm{d} \delta \mathrm{w}}{\mathrm{dt}}+\left[\left.\frac{\partial\left(\Delta \mathrm{p}_{\text {loop }}\right)}{\partial \mathrm{w}}\right|_{w_{0}}-\left.\frac{\partial\left(\Delta \mathrm{p}_{\text {pump }}\right)}{\partial \mathrm{w}}\right|_{w_{0}}\right] \delta \mathrm{w}=0
$$

The solution of equation (4) is

$$
\delta w(t)=\delta w(0)\left[\operatorname{Exp}\left(-\left[\left.\frac{\partial\left(\Delta p_{\text {loop }}\right)}{\partial w}\right|_{w_{0}}-\left.\frac{\partial\left(\Delta p_{\text {pump }}\right)}{\partial w}\right|_{w_{0}}\right] \frac{t}{I}\right)\right]
$$

Now, the system is said to be stable if $\lim _{t \rightarrow \infty} \delta w(t)=0$. Thus, equation (5) implies stability to flow excursions if 


$$
\left.\frac{\partial\left(\Delta \mathrm{p}_{\text {loop }}\right)}{\partial w}\right|_{w_{0}}>\left.\frac{\partial\left(\Delta \mathrm{p}_{\text {pump }}\right)}{\partial w}\right|_{w_{0}}
$$

Thus excursive instabilities can be predicted through the use of the steady state head vs. flow curve of the loop and the pump.

Most often for low system pressure and low inlet loss coefficients, there is a negative slope region of operati. 1 of the loop for which $\partial\left(\Delta \mathrm{p}_{\text {loop }}\right) /\left.\partial w\right|_{w_{0}}<0$. It can be seen that equation (6) implies that in this region, the system will be unstable unless the slope of the head vs. flow curve for the pump is even more negative. Thus Ledinegg flow instability is an important concern in setting SRS reactor power limits because it can lead to fuel dryout followed by rapid fuel temperature excursion and damage.

\section{Density Wave Oscillations}

The physical mechanism associated with density wave oscillations is fairly well understood. Basically, density waves oscillations are caused by the lag introduced in the system by the finite speed of propagation of density perturbations. Consider a boiling channel with a subcooled inlet subjected to a constant, parallel channel type pressure drop boundary condition. A perturbation in the inlet velocity, will create a propagating enthalpy perturbation, in the single phase region. The point at which boiling begins will then be perturbed by the arrival of this enthalpy wave. This will result into a propagating void fraction perturbation, and thus, a density wave in the two phase region.

Due to the change in flow rate and nonboiling length, there will be a perturbation in the two phase pressure drop. Since the pressure drop across the channel is externally imposed, there will be a feedback perturbation in the single phase pressure drop. Because of the lags associated with the finite speed of propagation of the enthalpy and void fraction perturbations, the resultant pressure drop perturbation in the two phase region and the corresponding feedback perturbation in the single phase region will normally be out of phase with the inlet velocity perturbation. Depending on the lag, the resultant pressure drop perturbation in the single phase region may either reinforce or attenuate the subsequent inlet velocity perturbation.

\subsubsection{Dynamic Problem Formulation}

\section{a) System Description}

The system shown in Fig. 1 represents a coolant channel of the Westinghouse Savannah River Site reactor. It consists of a channel having flow with heat addition between two volume capacitances which can insulate any systematic propagation of disturbances. The volume capacitances are the riser and downcomer. The system does not include the riser and the down comer, also it does not include components like pump and turbine. The system is 


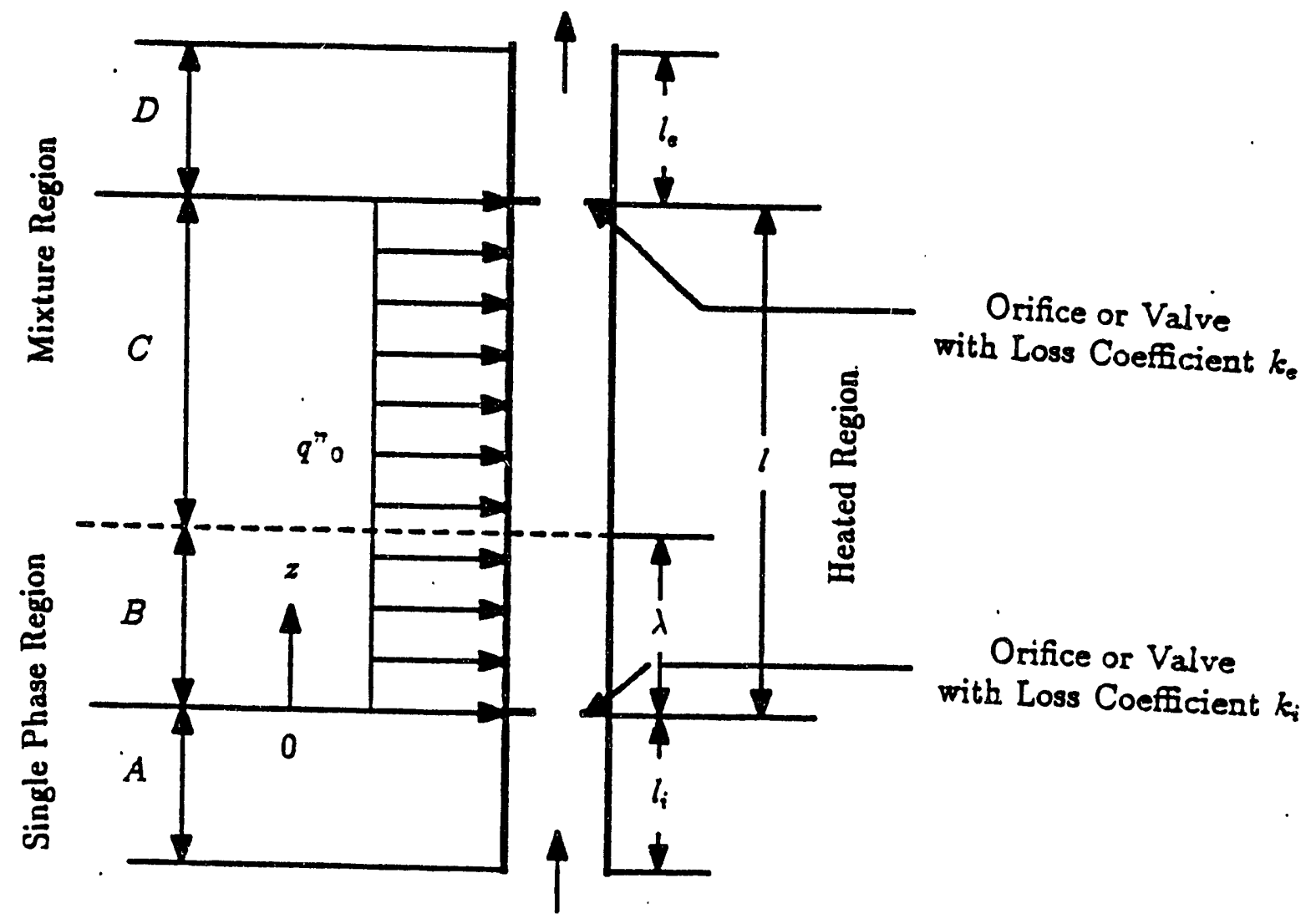

Figure 1 Schematic diagram of the System 
divided into four regions, namely, the upstream unheated region [A], the heated liquid region [B], the heated mixture region [C], and the downstream unheated region [D].

The thermodynamic process begins with the subcooled liquid of enthalpy $i_{1}$, entering the heated duct $[\mathrm{B}]$, with velocity $\mathrm{v}_{\mathrm{fi}}$. The heat flux imposed on region [B] is assumed to be constant. The liquid temperature and enthalpy increases as it moves through the heated duct, so assuming thermal equilibrium, the boiling boundary is taken to be the point at which the bulk liquid enthalpy reaches the saturation value $i_{\text {fs }}$. From here onwards, phase change takes place, and the mixture enthalpy and the void fraction increases as the two phase mixture moves through the heated mixture region [C]. This process can be assumed to take place at constant pressure, if the channel pressure drop is assumed to be relatively small compared to the absolute system pressure.

\section{b) Governing Equations}

Region[A]: In this region the flow is assumed to be incompressible and the process is taken as isenthalpic. The velocity field is obtained with the continuity equation. Using the velocity field the acceleration, friction, and gravity presure drops are obtained, including the pressure drop across the valve or the orifice at the entrance to the region [B], from the momentum equation.

$$
\begin{gathered}
v_{f O}=\frac{A_{c}}{A_{0}} v_{f i}(t) \quad \text { continuity eq. } \\
-\frac{\partial p}{\partial z}=\rho_{f}\left(\frac{\partial v_{f 0}}{\partial t}+v_{f 0} \frac{\partial v_{f 0}}{\partial z}+g_{0}+\frac{f_{0}}{2 D_{0}} v_{f 0}{ }^{2}\right) \quad \text { momentum eq. }
\end{gathered}
$$

For an orifice or a valve at the entrance of region $[B], \Delta p_{i}=k_{i} \rho_{f} v_{f i}{ }^{2}$.

The friction factor $f_{0}=f_{0}\left(P_{\text {system }}, v_{f 0}, \mu_{f}, \varepsilon_{0}, D_{0}\right)$.

Region[B]: In this region pressure and dissipation effects on liquid enthalpy are neglected. The thermal equilibrium between the phases is assumed. The boundary between region [B] and $[C]$ is taken to be at $z=\lambda$ where $i_{f}=i_{f s}$ (sat). Heat source is assumed to generate steady flux. The wall heat capacity is assumed to be small compared with to the fluid heat capacity. Using the continuity equation, the velocity field is obtained. The boundary between regions $[A]$ and $[B]$ is obtained from the energy equations, under the assumption of thermal equilibrium. 


$$
\begin{array}{cc}
\frac{\partial \rho_{\mathrm{f}}}{\partial t}+\frac{\partial \rho_{\mathrm{f}} \mathrm{v}_{\mathrm{f}}}{\partial z} & \text { continuity eq. } \\
\frac{\partial \mathrm{i}_{\mathrm{f}}}{\partial \mathrm{t}}+\mathrm{v}_{\mathrm{f}} \frac{\partial \mathrm{i}_{\mathrm{f}}}{\partial \mathrm{z}}=\frac{\mathrm{q}^{\prime \prime} \eta}{\rho_{\mathrm{f}} \mathrm{A}_{\mathrm{c}}} & \text { energy eq. } \\
-\frac{\partial \mathrm{p}}{\partial \mathrm{z}}=\rho_{\mathrm{f}}\left(\frac{\partial \mathrm{v}_{\mathrm{f}}}{\partial t}+\mathrm{v}_{\mathrm{f}} \frac{\partial v_{\mathrm{f}}}{\partial z}+\mathrm{g}+\frac{\mathrm{f}_{\mathrm{s}}}{2 \mathrm{D}} \mathrm{v}_{\mathrm{f}}^{2}\right) & \text { momentum eq. }
\end{array}
$$

The equation of state is $\rho_{\mathrm{f}}=\rho_{\mathrm{f}}\left(\mathrm{P}_{\text {system }}\right)=$ constant.

The friction factor $f_{s}=f_{s}\left(P_{\text {system }}, v_{f}, \mu_{f}, \varepsilon_{s}, D\right)$.

Region[C]: In this region the thermodynamic processes are assumed to take place at constant pressure, so that $p=\rho(i)$ only. With this assumption the momentum equation is decoupled from the continuity and energy equations. The continuity and energy equations can are solved to get the kinematic variables. Using the values of kinematic variables, the momentum equation is used to calculate the pressure drop. Here one dimensional time and area averaged drift flux model is used. calculate the pressure drop. The surface tension effects, axial conduction and normal stresses are neglected.

$$
\begin{gathered}
\frac{\partial \rho_{\mathrm{m}}}{\partial \mathrm{t}}+\frac{\partial \rho_{\mathrm{m}} \mathrm{v}_{\mathrm{m}}}{\partial \mathrm{z}} \quad \text { mixture continuity eq. } \\
\rho_{\mathrm{m}}\left(\frac{\partial \mathrm{i}_{\mathrm{f}}}{\partial \mathrm{t}}+\mathrm{v}_{\mathrm{m}} \frac{\partial \mathrm{i}_{\mathrm{m}}}{\partial \mathrm{z}}\right)=\frac{\mathrm{q}_{0}^{\prime \prime} \eta}{\mathrm{A}_{\mathrm{c}}}-\frac{\partial}{\partial \mathrm{z}}\left(\frac{\alpha \rho_{\mathrm{g}} \rho_{\mathrm{f}}}{\rho_{\mathrm{m}}} \bar{v}_{\mathrm{gj}} \Delta \mathrm{i}_{\mathrm{fg}}\right) \quad \text { mixture energy eq. } \\
-\frac{\partial \mathrm{p}}{\partial \mathrm{z}}=\rho_{\mathrm{m}}\left(\frac{\partial \mathrm{v}_{\mathrm{m}}}{\partial \mathrm{t}}+\mathrm{v}_{\mathrm{m}} \frac{\partial \mathrm{v}_{\mathrm{m}}}{\partial \mathrm{z}}+\mathrm{g}+\frac{\mathrm{f}_{\mathrm{m}}}{2 \mathrm{D}} \mathrm{v}_{\mathrm{m}}{ }^{2}\right)+ \\
\frac{\partial}{\partial \mathrm{z}}\left(\frac{\rho_{\mathrm{f}}-\rho_{\mathrm{m}}}{\rho_{\mathrm{m}}-\rho_{\mathrm{g}}} \frac{\rho_{\mathrm{g}} \rho_{\mathrm{f}}}{\rho_{\mathrm{m}}} \bar{v}_{\mathrm{gj}}{ }^{2}\right)
\end{gathered}
$$

Here the mixture enthalpy is $i_{m}=\left(\alpha \rho_{g} i_{g}+(1-\alpha) \rho_{f} i_{f}\right) / \rho_{m}$. The mixture density is $\rho_{m}=\alpha \rho_{g}+(1-\alpha) \rho_{f}$. For closure of the equations appropriate constitutive equations are used for drift velocity $\bar{v}_{g j}$, mixture friction factor $f_{m}$, and imposed heat flux $q^{\prime \prime} 0$.

Region[D]: In this region the pressure drop effects on mixture properties are neglected and the process is assumed to be isenthalpic. The kinematics of fluid is described by the continuity equation. The pressure drop calculations are similar to the region $[C]$, and the pressure drop across the valve or orifice located at the exit of the heated section [C] is obtained trough the loss coefficient.

From continuity equation at $z=1$, the boundary between region [C] and [D] 


$$
\begin{gathered}
v_{m e}=\frac{A_{c}}{A_{e}} v_{m}(1, t) . \\
-\frac{\partial p}{\partial z}=\rho_{m e}\left(\frac{\partial v_{m e}}{\partial t}+v_{m e} \frac{\partial v_{m e}}{\partial z}+g+\frac{f_{m e}}{2 D_{e}} v_{m e}{ }^{2}\right)+ \\
\frac{\partial}{\partial z}\left(\frac{\rho_{f}-\rho_{m e}}{\rho_{m e}-\rho_{g}} \frac{\rho_{g} \rho_{f}}{\rho_{m e}} \bar{v}_{g j}{ }^{2}\right) \text { momentum eq. }
\end{gathered}
$$

Isenthalpic condition represents the energy equation.

\subsubsection{Method of Solution}

The objective is to obtain the transient response of the system, and determine the stability criteria for the system. The origin of axial coordiante is chosen to be the boundary between regions $[A]$ and $[B]$, i.e. $z=0$ at the boundary of $[A]$ and $[B]$.

The initial and the bound?ry conditions are: At $z=0, t \geq 0$,

$$
\begin{aligned}
& \rho_{f}=\rho_{f}\left(P_{\text {system }}\right), P=P_{\text {system }}=\text { constant } \\
& i_{f}=i_{1}=\text { constant, } i_{f}=i_{f s}\left(P_{\text {system }}\right), v_{f}=v_{f}(t)=v_{f i}+\delta v(t) .
\end{aligned}
$$

The velocity perturbation is modeled using frequency response: $\delta v(t)=\varepsilon e^{\text {st }}$, where $s=a+j w$. Here, $a$ is the amplification coefficient of a particular oscillation mode and $w$ is the angular frequency. The perturbation analysis is assumed to be linear, in the sense that is assumed to be infinitesimal, compared to finite $v_{f}$. Thus, only the first order terms in are retained, higher order terms are neglected. The steps in the solution procedure are listed.

1. Use kinematics with boundary conditions to get steady state and perturbed solutions for kinematic variables.

2. Use dynamics to get steady state and perturbed solution for pressure drop.

3. Along with the response of pressure perturbation, tise heat flux boundary condition q" 0 and rheologiacl constitutive relation for friction factor $\mathrm{f}_{\mathrm{m}}$ to get the characteristic equation: $\delta(\Delta \mathrm{p})=\mathrm{Q}(\mathrm{s}) \delta(\mathrm{v})$ or $\delta(\mathrm{v})=\delta(\Delta \mathrm{p}) / \mathrm{Q}(\mathrm{s})$.

The asymptotic stability of the system is determined by the nature of roots of the characteristic equation $Q(s)=0$.

\subsubsection{Presentation of Results}

Stability Plane :

To present the stability boundaries in a two dimensional plane, two representative parameters as the coordinates, are required. For constant system pressure, inlet velocity, given fluid and geometry, the Froude number, the Reynolds number, the drift number and the 
density ratio are fixed. Hence, the subcooling and the phase change numbers are useful as the coordinates of the stability plane. Operational domain in the stability plane is bounded by the physical restriction on heat flux and subcooling. For positive subcooling, if $\Delta \mathrm{i}_{\mathrm{s}}$ denotes the maximum possible subcooling, then

$$
0 \leq \mathrm{N}_{\text {Sub }} \leq \frac{\Delta \mathrm{i}_{\mathrm{s}}}{\Delta \mathrm{i}_{\mathrm{fg}}} \frac{\Delta \rho}{\rho_{\mathrm{g}}}
$$

For boiling in the channel, without superheating,

$$
N_{p c h}-\frac{\Delta \rho}{\rho_{g}}<N_{\text {Sub }}<N_{p c h}
$$

For constant exit quality,

$$
N_{\text {Sub }}=N_{\text {pch }}-x_{e} \frac{\Delta p}{\rho_{g}}
$$

The dimensionless length of the boiling region is given by

$$
\lambda^{*}=\frac{\lambda}{1}=\frac{\mathrm{N}_{\text {Sub }}}{\mathrm{N}_{\mathrm{pch}}}
$$

Equations (17), (18), (19) and (20) represent the basic characteristics in the stability plane. Figure (2) shows the stability plane with these basic characteristics.

Two computer codes, which are currently under development will be used for the numerical analysis. One code determines the neutral stability curves, and the other tests chosen points for stability. The parametric equations describing the neutral stability curve are obtained by separating the real and imaginary parts of the shifted characteristic equation. The limiting value $w \rightarrow 0$ makes the imaginary part zero, thus the initial value of the real part decides the excursive stability boundary. The stability plane is bounded by the finite domain for its coordinates. A nodal mesh can be created by constant subcooling and quality lines. The crossover frequencies can be found by interpolation. These are substituted into the real part of the shifted characteristic equation and for non zero values of the real part, the stability test is carried out. When the real part is zero, the point lies on the stability boundary. The excursive stability boundary is also added. The stability boundaries are constructed by covering the entire mesh. The test of stability at any point is carried out by applying the stability test criterion. The real and imaginary parts of the shifted characteristic equation are calculated, the result is plotted in the $s^{*}$ plane, and the stability test criterion is applied.

The input data for the computer code have been obtained from Westinghouse Savannah River Company and Babcock and Wilcox Research and Development Center at Alliance, Ohio. The data consist of reactor geometry and operating conditions. The following modifications are needed in the model: 
1. The inlet unheated section consists of many sections of different hydraulic diameters and loss coefficients due to area expansion or reduction. So, the model for inlet unheated section is used for each section individually, and then the results are summed up for all the unheated section.

2. The exit loss in the form of area reduction or expansion does not occur at the exit of the heated assembly. So the exit orifice pressure drop term has to be modified by evaluating it at the proper location.

Currently the solution to the characteristic equations as described in the method of analysis have been obtained. The parametric equations describing the nuetral stability curve and the stability test criterion have been obtained. The details of the analysis are given in [16]. The initial results of the analysis indicate the existence of first order and and higher order instabilities in the transient operating conditions. The effect of the fluid inlet subcooling has a stabilizing effect on the system except at very low subcooling. At low flow rate the instability is easily encountered. Also the instabilities are encountered at low system pressure and high heat flux.

\subsection{Experimental Study}

\subsubsection{Design Considerations}

A scaling study for simulating the heavy water reactor by Freon 113 was carried out using the previously developed thermalhydraulic similarity laws $[17,18]$ as well as several low flow CHF criteria [1-3]. Based on this study the experimental loop design has been carried out. In Table 1 and 2 the comparison between parameters of the model and the prototype system are given. The model georietry, working fluid and the operating conditions were chosen with consideration to the cost effectiveness and scaling. The simulated loop correctly scales the phase change, subcooling and friction numbers. These insure that the dynamical phenomena due to the void propagation, enthalphy waves and pressure drop are simulated.

The CHF at low flow and low pressure condition is very complicated phenomena influenced by both the loop dynamical characteristics and local conditions. In order to simulate the CHF conditions, several existing CHF correlations have been examined using the nondimensional parameters developed by Mishima and Ishii [1-3]. The results of the location of CHF in these parameter domain are shown in Figs. 3 and 4 for the case of the prototype (Savannah River Reactors) and one for the simulation loop. Although, the exact locations of CHF are not identical, the general behaviors are very similar between these systems. Therefore, it is expected that the simialr CHF mechanisms can be encountered in the Purdue simulation loop. The velocity relations between the model and the prototype as well as the heat flux relations are shown in Figs. 5 and 6 . It can be seen that the velocity is reduced by a factor of three. The heat flux necessary to reach CHF is reduced by a factor of 2.5 in the 
simulation loop.

\subsubsection{Experimental Facility}

An experimental test facility was constructed to study the critical heat flux (CHF) phenomenon at low flow and low pressure conditions for vertical flow of Freon-113, as the test fluid. The annular geometry of the test section is designed to simulate the SRS (Savannah River Site) reactor Mark 22 assembly flow conditions as discussed in the design considerations. The test loop has a provision for both the down flow and up-flow experiments. The schematics of the experimental facility is shown in Fig. 7. Central to the test facility, which consists mainly of delivery and recovery systems of the test fluid, Freon-113, in addition to various instrumentations to monitor and record the data, is the test section. It consists of a vertical transparent glass tube and a cartridge type heater located inside the glass tube with annular space for fluid flow. Use is made of the transparent test section to investigate the hydrodynamic aspects of the critical heat flux phenomenon in addition to the conventional heat transfer studies.

A detailed description of the test facility is given below:

\section{a. Test section}

The cartridge heater at the center of the test section is $2.17 \mathrm{~m}$ long, $1.2 \mathrm{~cm}$ OD with a maximum power of $6.72 \mathrm{KW}$. The heated length of the heater is $1.88 \mathrm{~m}$ long which is equal to the length of the beaded glass tube that makes the outer wall of the annular space of the test section with $1.9 \mathrm{~cm} \mathrm{ID}$. The annular gap is $0.35 \mathrm{~cm}$ wide which is equivalent to the hydraulic radius of the annular test section. The beaded glass tube is fused at both ends with 1 inch conical connectors for assembling with the rest of the loop. Sixteen $0.21 \mathrm{~mm}$ OD K-type Chromel-Alumel thermocouples are spot welded on the heater surface to monitor and record the surface temperature of the heater during the experimental runs. The thermocouples are covered with high-temperature thermally conductive cement to help fixing them to the heater surface. The thermocouples are equally spaced near the center of the heater but are more closely spaced near the two ends since dry patches are expected more frequently near the outlet. The locations of the sixteen thermocouples are shown in Fig. 8. The azimuthal location of each thermocouple differs from the rest of the thermocouples with respect to the heater surface, in order to get the CHF location as closely as possible. The azimuthal locations of the thermocouples are not shown, however, in Fig. 8.

Four spacer-rings are used to center the heater in the test section. Use is made also of the spacer-rings to guide the thermocouple wires away from the heater surface such that the wires extend along the glass wall. Eight thermocouples extend from the top of the test section and the remaining eight extend from the bottom. Two Teflon flanges are attached at both ends of the test section. Each flange has three side holes; two for thermocouple lead wires and one 


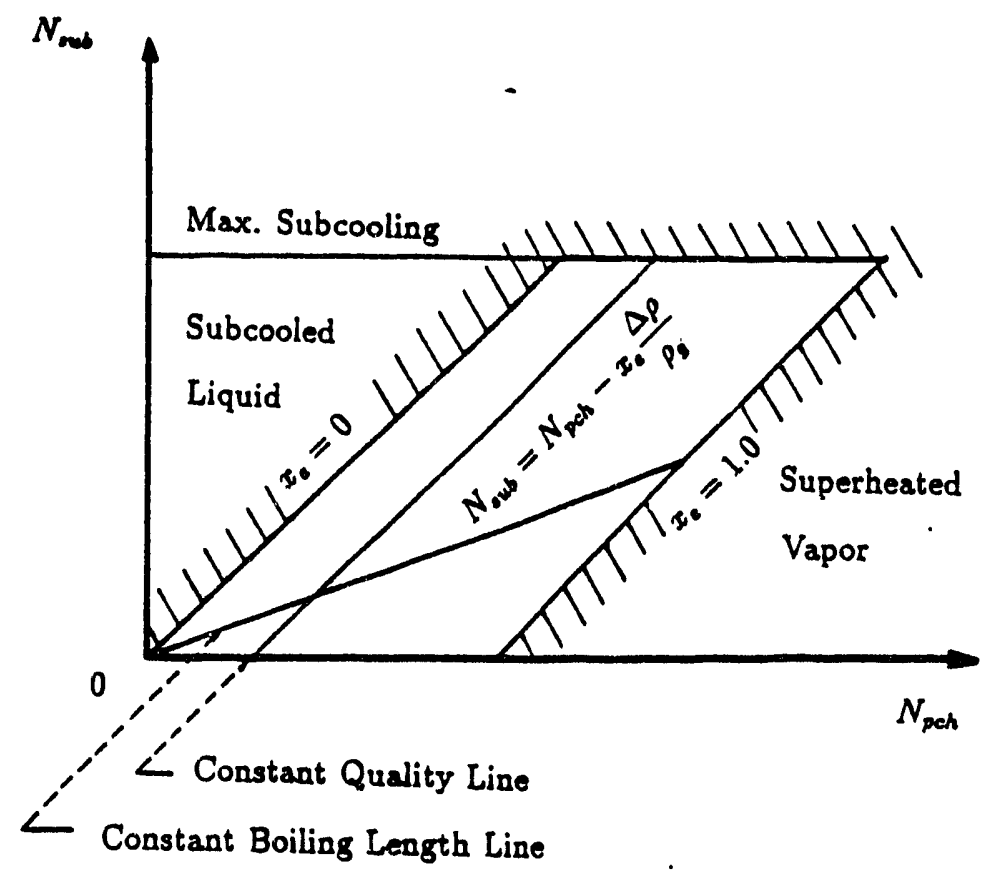

Figure 2 Stability plane with basic characteristics

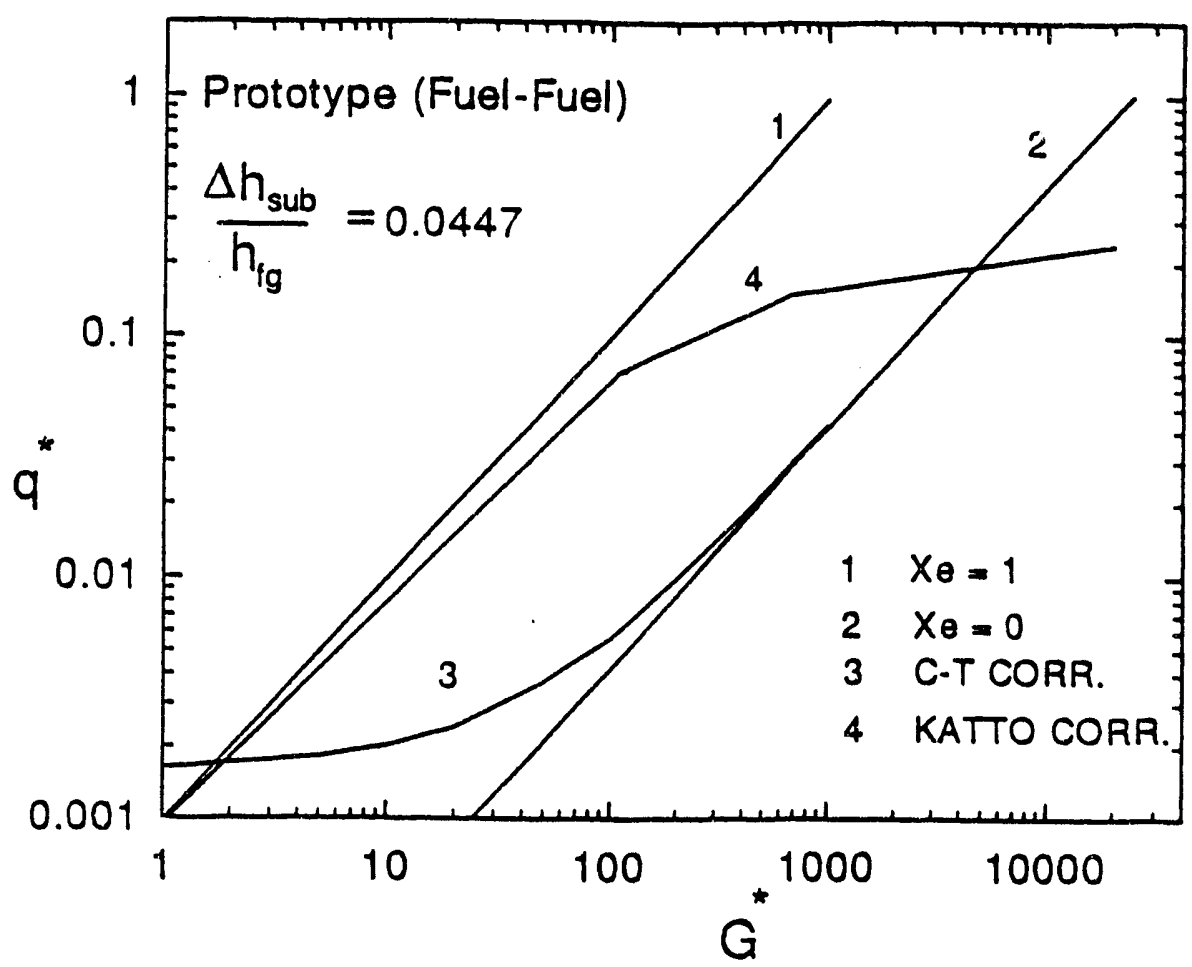

Figure $3 \mathrm{CHF}$ correlations for prototype system 
Table 1 Parameters for prototype (Fuel-Target) and model

\begin{tabular}{lcc}
\hline & Prototype (Fuel - Target) & Model \\
\hline Geometry & Concentric Annulus & \\
Heated Length $L_{H}(\mathrm{~m})$ & 3.6 & $1.587 \times 10^{-2}$ \\
Equivalent Diameter $D_{H}(\mathrm{~m})$ & $1.817 \times 10^{-2}$ & $7.3 \times 10^{-2}$ \\
Heated Area $A_{B}\left(\mathrm{~m}^{2}\right)$ & 0.919 & Freon-113 \\
Fluid & Water & 101 \\
Pressure $(\mathrm{kPa})$ & 138 & $V_{m}-1$ \\
Velocity $(\mathrm{m})$ & $V_{p}-2$ & $\# 1, \quad \# 2$ \\
Subcooling $\frac{\Delta h_{s u b_{1}}}{h_{f g}}$ & $\# 1, \quad \# 2$ & $0.265, \quad 0.137$ \\
CHF $(C-T) q_{c}{ }^{\prime \prime}\left(k W / \mathrm{m}^{2}\right)$ & $16-257,16-141$ & $6-131,6-70$ \\
Power $(\mathrm{kW})$ & $\ldots .0447,0.0231$ & 6 \\
\hline
\end{tabular}


Table 2 Parameters for prototype (Fuel-Fuel) and model

\begin{tabular}{|c|c|c|}
\hline & Prototype (Fuel - Fuel) & Model \\
\hline Conmatma & Concentric Annulus & Annulus \\
\hline Geometry & & $(Q D)$ \\
\hline Heated Length $L_{H}(\mathrm{~m})$ & 3.6 & 1.83 \\
\hline Equivalent Diameter $D_{H}(\mathrm{~m})$ & $1.361 \times 10^{-2}$ & $1.587 \times 10^{-2}$ \\
\hline Heated Area $A_{H}\left(\mathrm{~m}^{2}\right)$ & 1.506 & $7.3 \times 10^{-2}$ \\
\hline Fluid & Water & Freon-113 \\
\hline Pressure (kPa) & 138 & 101 \\
\hline $\operatorname{Velocity}(\mathrm{m})$ & $V_{p}-2$ & $V_{m}-1$ \\
\hline & $\# 1, \quad \# 2$ & $\# 1, \quad \# 2$ \\
\hline Subcooling $\frac{\Delta h_{\text {sub }}}{h_{f g}}$ & $0.0447, \quad 0.0231$ & $0.265, \quad 0.137$ \\
\hline$C H F(C-T) q_{c} "\left(k W / m^{2}\right)$ & $15-195,15-108$ & $6 \cdot 131,6 \cdot 70$ \\
\hline Power (kW) & -.-. & 6 \\
\hline
\end{tabular}




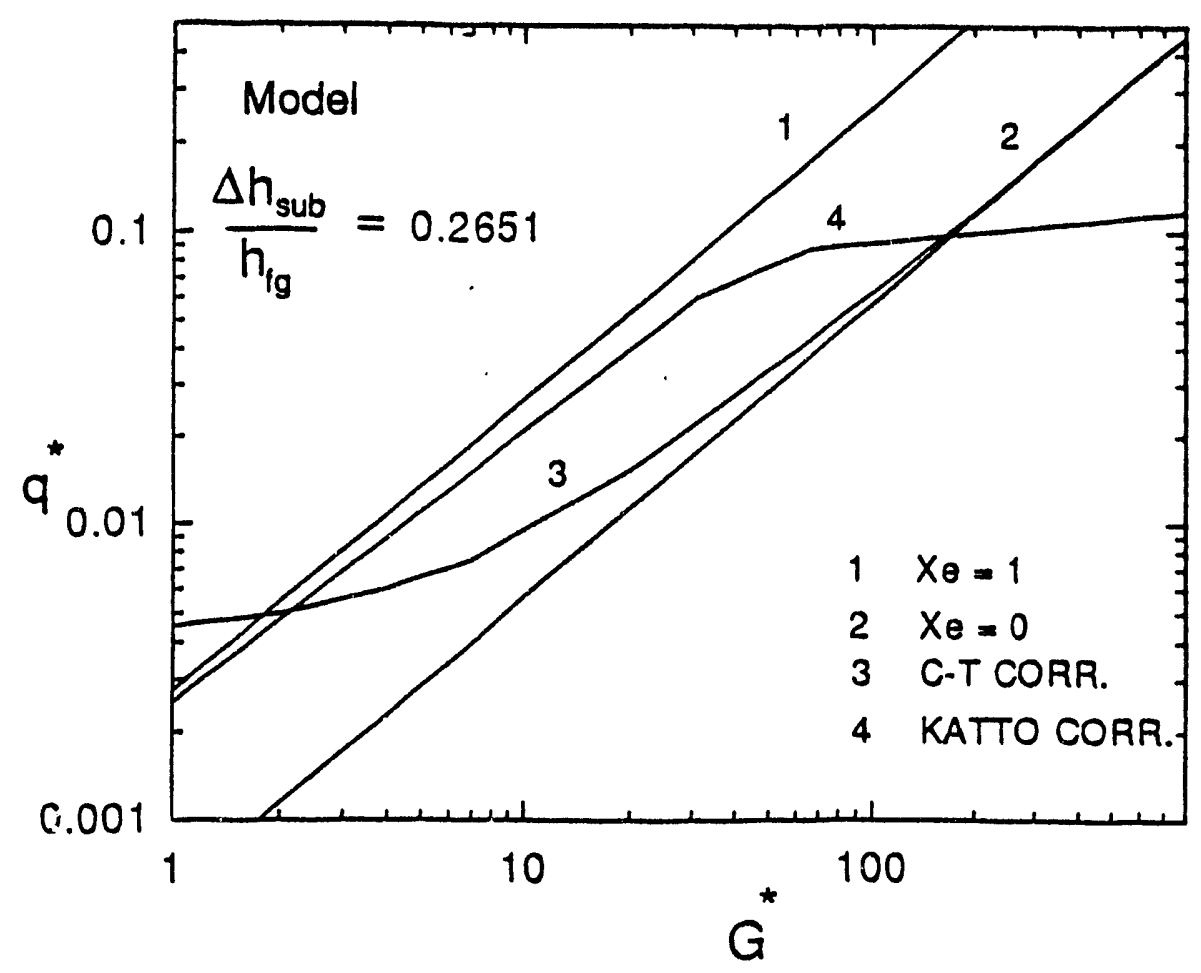

Figure 4 CHF correlations for model system

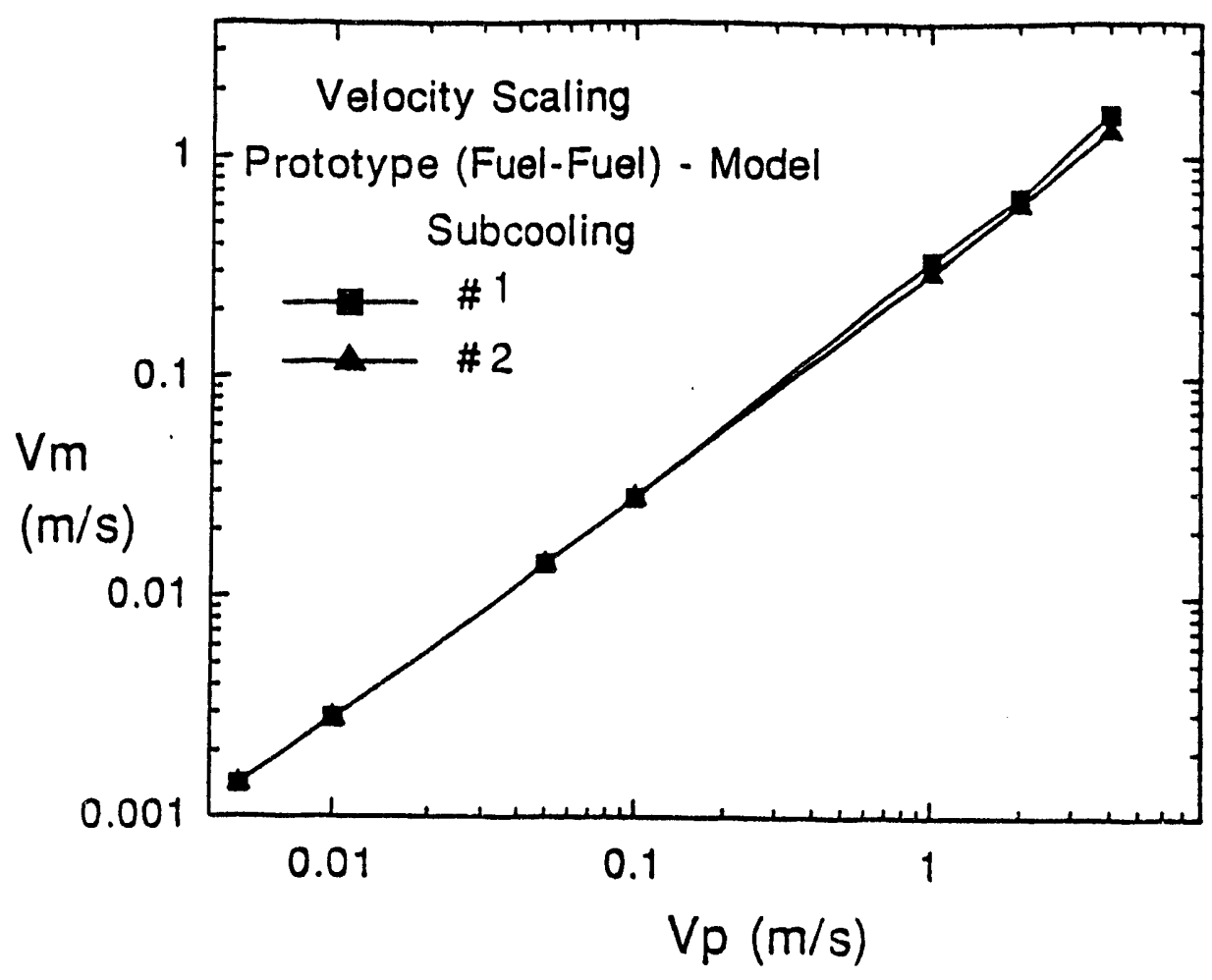

Figure 5 The similarity scaling of velocity between prototype and model 


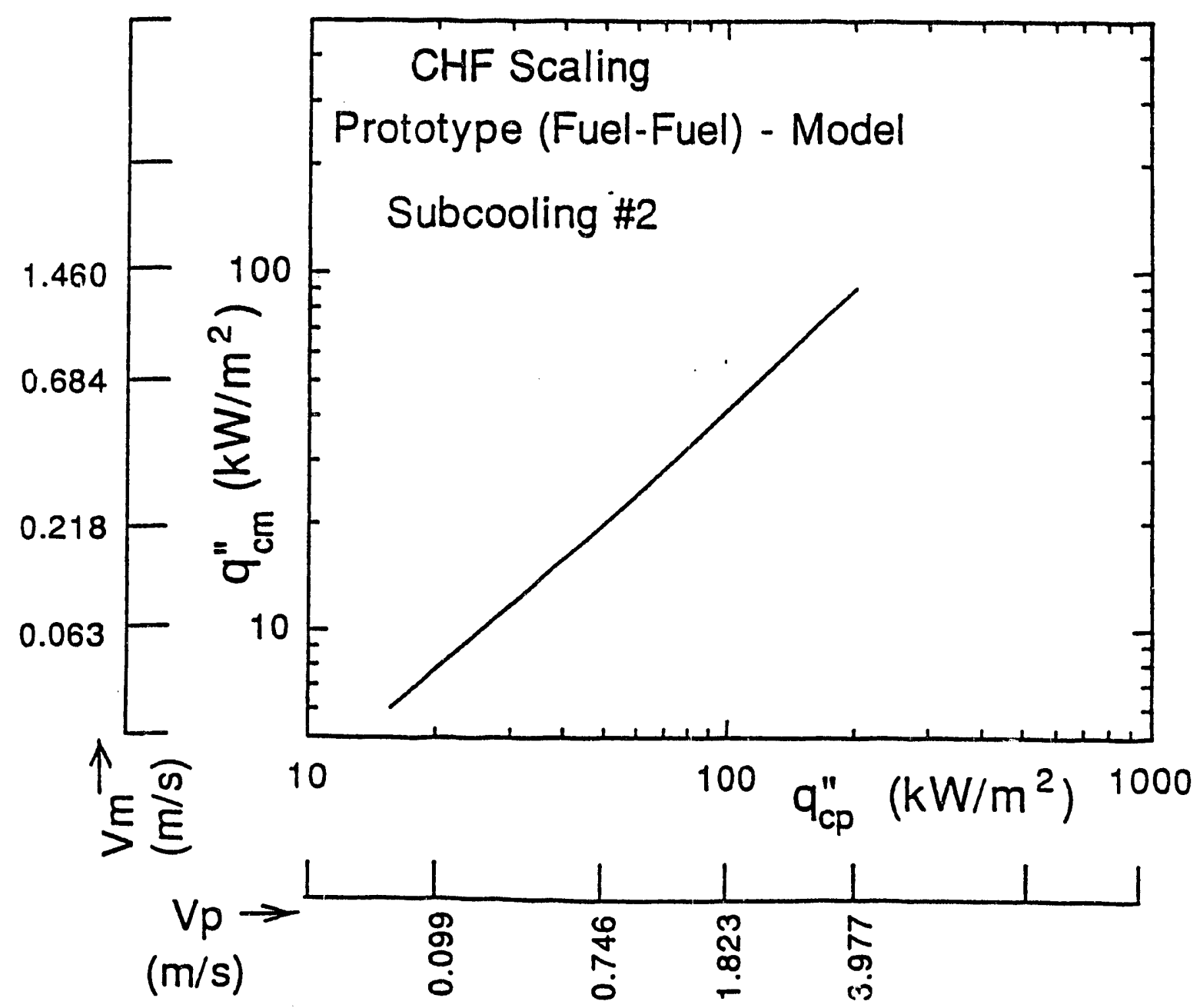

Figure 6 The CHF scaling between the prototype and the model 
serves as pressure tap connection.

The upper and and lower plena are made of 2 inch Pyrex crosses. The connections to the test section and the delivery and recovery lines are made via 2 to 1 inch Pyrex reducers. The test section is equipped with two flow resistance devices made of hard Teflon in the shape of a tapered plug as can be seen in Fig. 8. A male and a female threads are adopted in making the traversing mechanism of the flow restriction devices which produces various degrees of flow restriction by reducing/opening the flow area. The lower plenum is mounted on a steel flange which, in turn, is mounted on the main loop structure. Both the upper and the lower steel flanges have three holes, $3 / 8$ inch NPT in size, for the flow restriction device traversing mechanism, the main heater, and a pressure tap connection.

\section{b. Freon delivery and recovery system}

A $2 \mathrm{HP}$ centrifugal pump, capable of delivering $145 \mathrm{gpm}$ maximum flow rate and $67 \mathrm{ft}$ of maximum head, is used to supply Freon to the test section. The pump is installed at the lowest point of the test loop and a draining valve is attached to it. A by-pass line with a ball valve is connected to the inlet and outlet of the pump to regulate the flow rate to the test section. Downstream of the pump a preheater is installed to control the Freon temperature entering the test section. The $2 \mathrm{KW}$ galvanized steel preheater can increase the Freon temperature, flowing at $30 \mathrm{~cm} / \mathrm{sec}$ in a 1 inch diameter tube, by $10 \mathrm{C}$. Downstream of the preheater the system branches into two: upflow and downflow branches. To direct the flow in either direction a set of two valves (two sets are available) is closed which will force the Freon to follow, say, in the upward direction in the test section. The test section outlet, for both up and down flow cases, is connected to the inlet of a condenser which consists of double sets of coils submerged in a water bath. The outer set has 22 coils with $43 \mathrm{~cm}$ OD and $32.4 \mathrm{~cm} \mathrm{ID}$, and the inner set has 15 coils with $31 \mathrm{~cm} \mathrm{OD}$ and $28 \mathrm{~cm} \mathrm{ID.} \mathrm{The} \mathrm{outlet} \mathrm{of} \mathrm{the}$ condenser is connected to a subcooler which controls the Freon subcooling, if needed, required for the experimental runs. The subcooler consists of a chest-type freezer with a bath of Ethylene Glycol in which a set of 17 coils with $43 \mathrm{~cm}$ OD and $32.4 \mathrm{~cm}$ ID is submerged. If no subcooling is desired, the Freon emerging from the condenser could be directed to by-pass the subcooler to the pump inlet.

A 1 inch $\mathrm{ID}$ by-pass tube is connected to the test section. The flow through the by-pass line is controlled by a ball valve and is measured by a turbine flow meter. Ten tubular bandtype heaters of $495 \mathrm{~W}$ power each are mounted on the by-pass line and are used to match the temperature conditions of the flow inside the by-pass line with the temperature conditions inside the test section. The by-pass line isolates the flow disturbances and/or instabilities generated in the loop from the test section instabilities.

The test loop is supplemented with a 15 gallon, galvanized steel degassing tank located at the highest point of the test section. Two immersion heaters of $600 \mathrm{~W}$ power each are screwed 


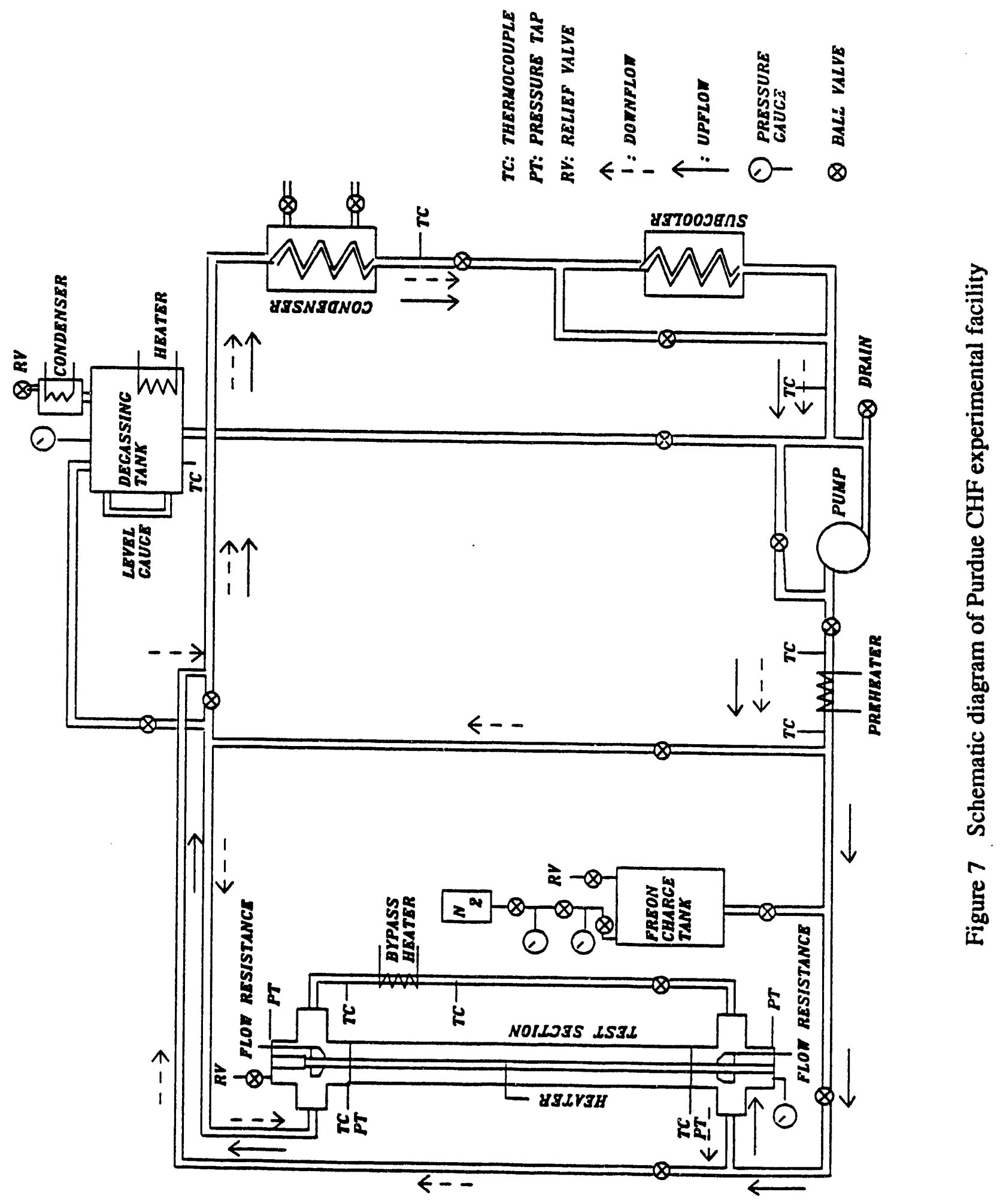




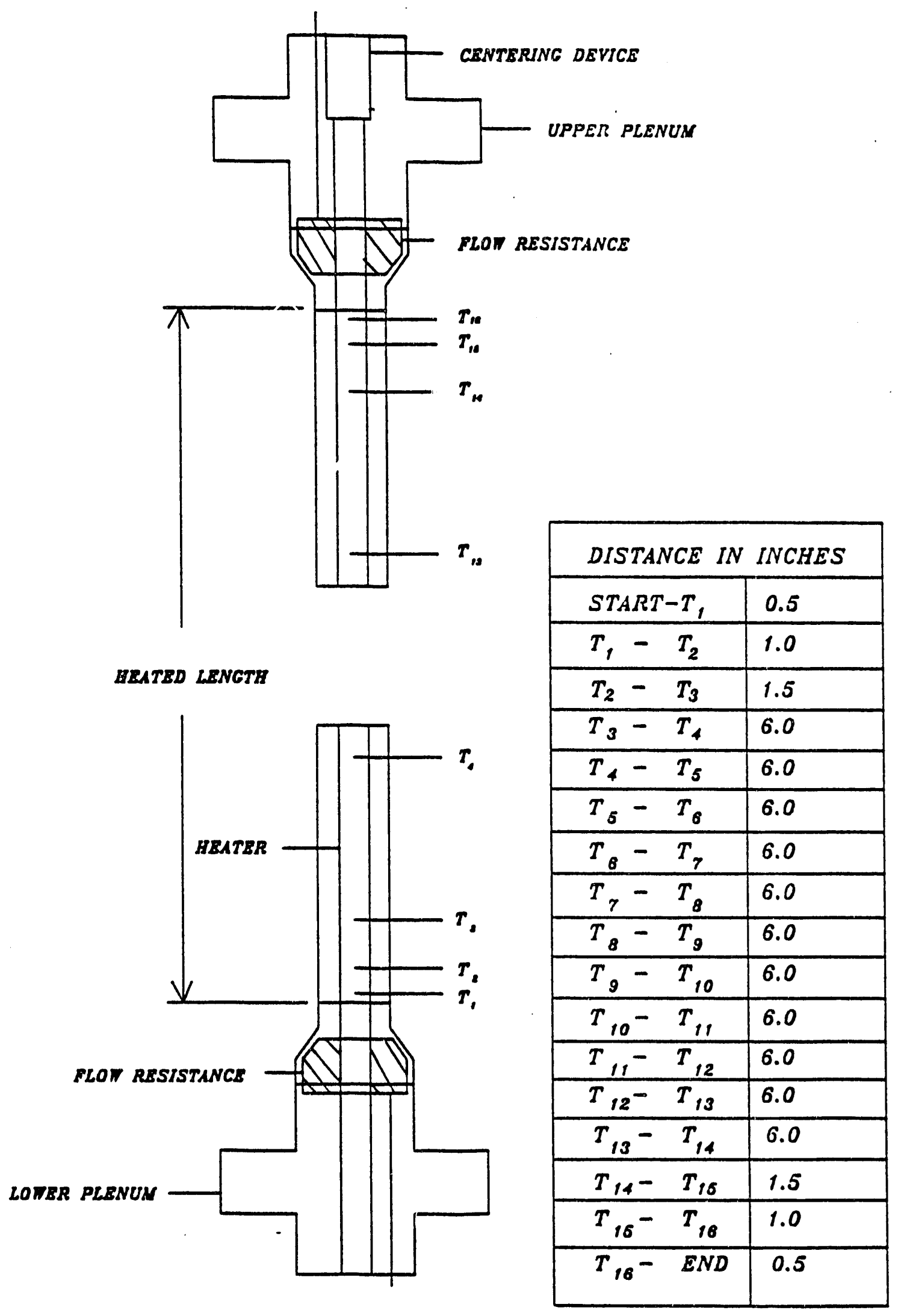

Figure 8 Test section and location of the heater thermocouples 
at the bottom of the degassing tank which is equipped with a level gauge to monitor the Freon level inside the degassing tank. A condenser is attached to the degassing tank that utilizes water to cool a set of 28 coils with $6.35 \mathrm{~cm}$ OD and $5 \mathrm{~cm} \mathrm{ID.} \mathrm{The} \mathrm{degassing} \mathrm{tank} \mathrm{along} \mathrm{with}$ the heaters and the condenser could be used to regulate the pressure in the loop resembling a pressurizer in a reactor.

The loop has four relief valves that are connected to the test section lower plenum, the test section upper plenum, positive pressure line of the degassing tank, and to the negative pressure line of the degassing tank with cracking pressures of $210 \mathrm{kPa}(30 \mathrm{psi}), 210 \mathrm{kPa}(30 \mathrm{psi})$, $21 \mathrm{kPa}(3 \mathrm{psi})$, and $-6.89 \mathrm{kPa}(-1 \mathrm{psi})$ respectively. The outlets of the relief lines are connected to a dump tank which, in turn, is connected to the atmosphere. The dump tank is equipped with a $6.89 \mathrm{kPa}(1 \mathrm{psi})$ cracking pressure relief valve.

Two solenoid valves are mounted on the outlet of the preheater and the inlet to the condenser to isolate the test section from the rest of the loop in case of an accident or unanticipated breakage of the test section. The Freon circulating through the loop is regularly filtered using a 25 micrometer pleated paper filter cartridge to trap any impurities or dirt that might exist in the Freon stream. The test section assembly is encased in a box of transparent, anti-shattering Lexan sheets to provide protection for personnel and instrumentations against and breakage of the test section.

\section{c. Instrumentasion}

The parameters that are monitored and recorded in this experiment are: temperature, pressure, flow rate, degree of flow restriction, and heaters' power. Data are measured and recorded via MetraByte's DAS-8PGA/EXP-16 data acquisition system, whereas Labtech Notebook software is used to manage and analyze the collected data. The DAS-8PGA/EXP16 system contains the original eight analog input channels in the DAS-8PGA box, in addition to two EXP-16 multiplexer boxes with sixteen analog input channels in each box, variable gain setup switches, and cold junction sensing and compensation circuitry for direct temperature measurement using thermocouples. The sampling rate for all channels is $1 \mathrm{~Hz}$ and the duration of continuous sampling is 10 minutes.

Description of the instrumentation is detailed in the subsections below:

i) The test section heater surface temperature is measured using sixteen $0.21 \mathrm{~mm}$ OD K-type Chromel-Alumel thermocouples that are spot-welded on the heater surface and are covered with high temperature thermally conductive cement. An ice box is installed to serve as a reference point for the heater thermocouples. If CHF occurs in a heat flux controlled experiment, the wall temperature rises sharply and may result in a burnout of the heater if the power is not tripped immediately. To avoid such a drastic deterioration in the surface temperature, a feedback control circuit is built with a solid state relay that cuts the power off 
the heater if the surface temperature exceeds $150 \mathrm{C}$ at any point on the heater surface. The trip circuit will also cut the power off the heater if any of the thermocouples fails to function properly. The sixteen thermocouples are connected to the EXP-16 multiplexer box number 1 which has a set gain of 1000 . The power to the heater could also be cut off manually using an on-off switch located on the electronic circuit box. Fig. 8 shows the locations of the heater thermocouples. The power trip circuit was calibrated to trip the heater at a temperature of $150 \mathrm{C}$ for each thermocouple using a known temperature source.

ii) The temperature of the test fluid is monitored in $\because$ veral locations around the loop in order to establish the temperature conditions designated ior the specific experimental run. The fluid temperature measurements are made with K-type Chromel-Alumel thermocouples of 1/16 inch diameter, at nine locations in the test loop. the thermocouples are directly connected to EXP-16 multiplexer box number 0 set to a gain of 50 and taking advantage of the cold junction sensing and compensation circuitry. The code name and location of each thermocouple is given below:

1. FT1 Test section inlet fluid temperature (upflow case)

2. FT2 Test section outlet fluid temperature (upflow case)

3. FT3 Degassing tank fluid temperature

4. FT4 Condenser outlet fluid temperature

5. FT5 Subcooler outlet fluid temperature

6. FT6 Preheater inlet fluid temperature

7. FT7 Preheater outlet fluid temperature

8. FT8 By-pass line outlet temperature (upflow case)

9. FT9 By-pass line inlet temperature (upflow case)

All thermocouples were individually checked against malfunctioning and/or wrong connection. The thermocouples used are made of 304 SS sheathed and ungrounded.

iii) Two turbine flow meters are installed in the loop to measure the flow rate of Freon at two locations. Information given below contain location, purpose, and range of each flow meter:

1. Main flow meter: located near the inlet to the preheater and is used to measure the flow rate in the loop with range of $0.75-7.5 \mathrm{gpm}$.

2. By-pass flow meter: located on the test section by-pass line and is used to measure the fiow rate in the by-pass line with range of $0.75-7.5 \mathrm{gpm}$.

Both turbine flow meters were calibrated by manufacturer. The calibration curve for the turbine flow meters is shown in Fig. 9. The output signals of the turbine flow meters are directed to the DAS-8PGA box (with set gain of 1). Independent DC power supply is 
provided for each flow meter with an input voltage of $12 \mathrm{VDC}$.

iv) Pressure measurements are made at five locations in the test loop. Three differential diaphragm-type pressure transducers are used to measure the pressure drop across the lower plenum, the test section and the upper plenum with ranges of $14 \mathrm{kPa}, 35 \mathrm{kPa}$ psi, and $35 \mathrm{kPa}$ psi, respectively. Mating connectors are used to connect the pressure transducers to the carrier demodulator which is used to condition the pressure signals and hence to send them to DAS8PGA data acquisition box (with set gain of 1 ). The three differential pressure transducers are calibrated using hydrostatic head of water column. The calibration curves of the three pressure transducers are shown in Fig. 10.

The remaining two pressure measurements are made with absolute pressure gauges. The system pressure is measured at the lower plenum using a pressure gauge with range of 0 $1400 \mathrm{kPa}(0-200 \mathrm{psi})$, whereas the degassing tank pressure is measured using a gauge with a range of $0-210 \mathrm{kPa}(0-30 \mathrm{psi})$. Both pressure gauges are fixed at the main control panel of the test loop.

v) Control panel: The powers of the main heater, the preheater, the by-pass heaters and the degassing tank heaters are monitored using voltage and current meters which are fixed to the control panel. The power of each heater can be varied using a power variac connected to each heater. The control panel also has two on-off switches for control of solenoid valves, system and degassing tank pressure gauges, turbine flow meters output voltage, and power switches for the heaters and the pump.

The photograph of the Purdue CHF experimental facility is shown in Fig. 11.

\subsubsection{Preliminary Results}

A set of preliminary experiment were designed and performed to test the performance of the various instrumentations in the test loop. After assuring the adequacy of the different components of the test loop, such as the flow meters, the pressure transducers, the heater thermocouples, a second set of experiments were carried out investigating the hydrodynamic behavior of the test fluid under boiling conditions. The first attempt was to study the effect of increasing the heat flux on the system while maintaining the rest of parameters constant. It is expected that, with minimal flow restriction at the inlet to the test section and substantial restriction at the exit of the test section, the flow instability will occur with increasing heat flux. Hence the experiment was performed with constant inlet flow rate to the test section of $35 \mathrm{~cm} / \mathrm{sec}$, no inlet flow restriction, substantial outlet flow restriction, and constant inlet subcooling.

The bypass line to the test section is kept open such that when the system reaches the instability, the reduction in fluid flow in the test section will be compensated by increasing the flow rate in the bypass line in order to maintain steady operating conditions. The heater power 


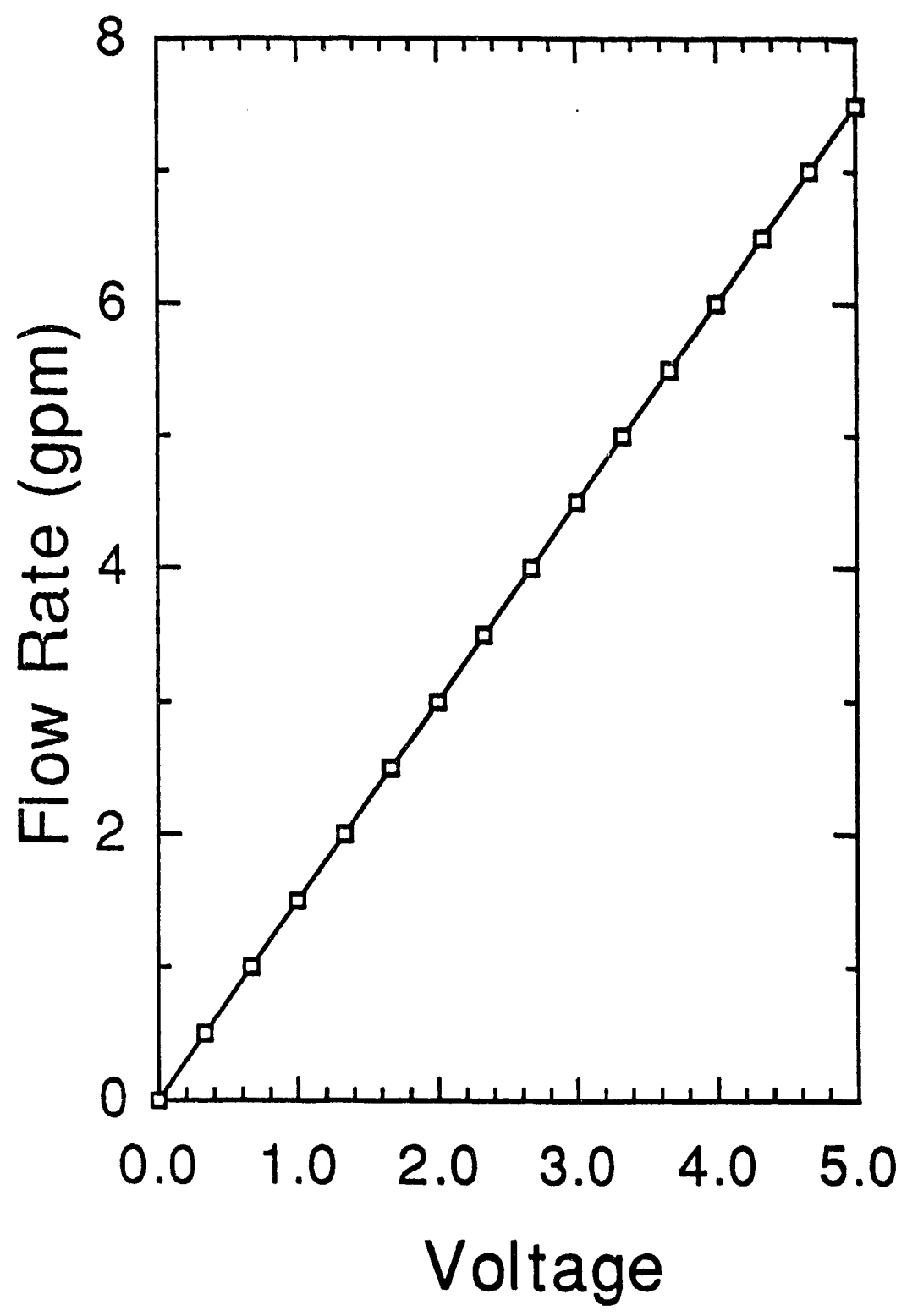

Figure 9 Calibration curve for turbine flow meter 

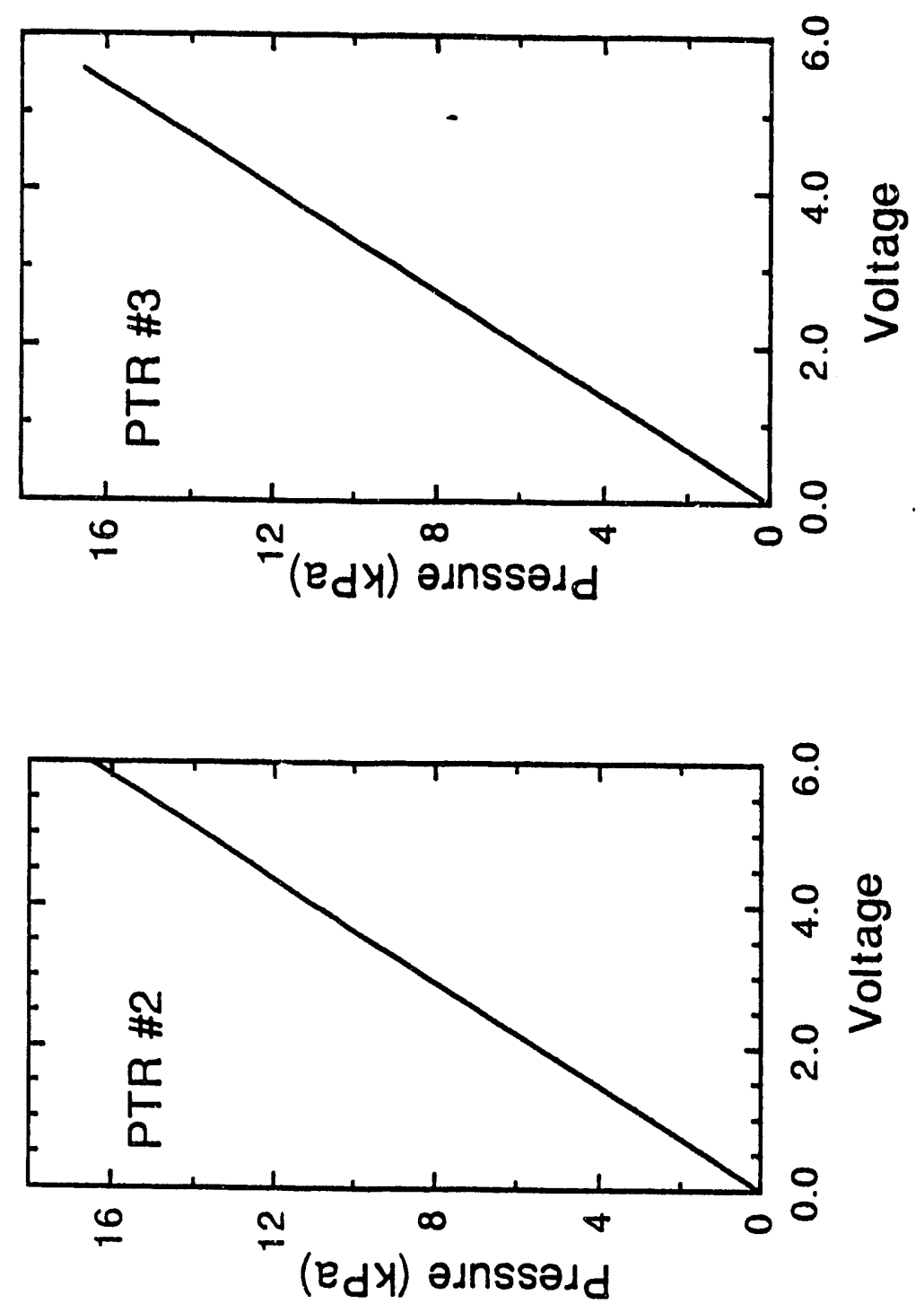

造

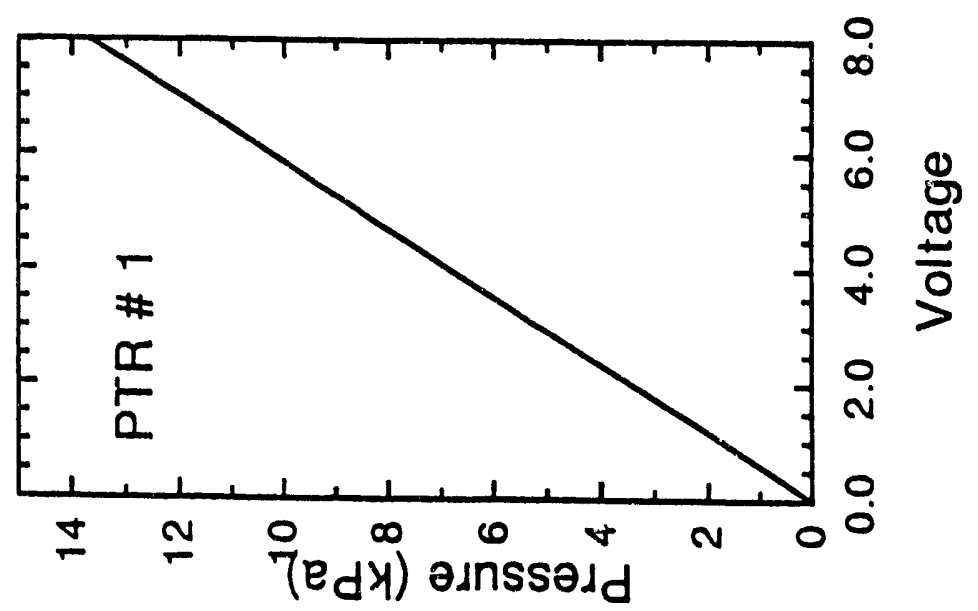




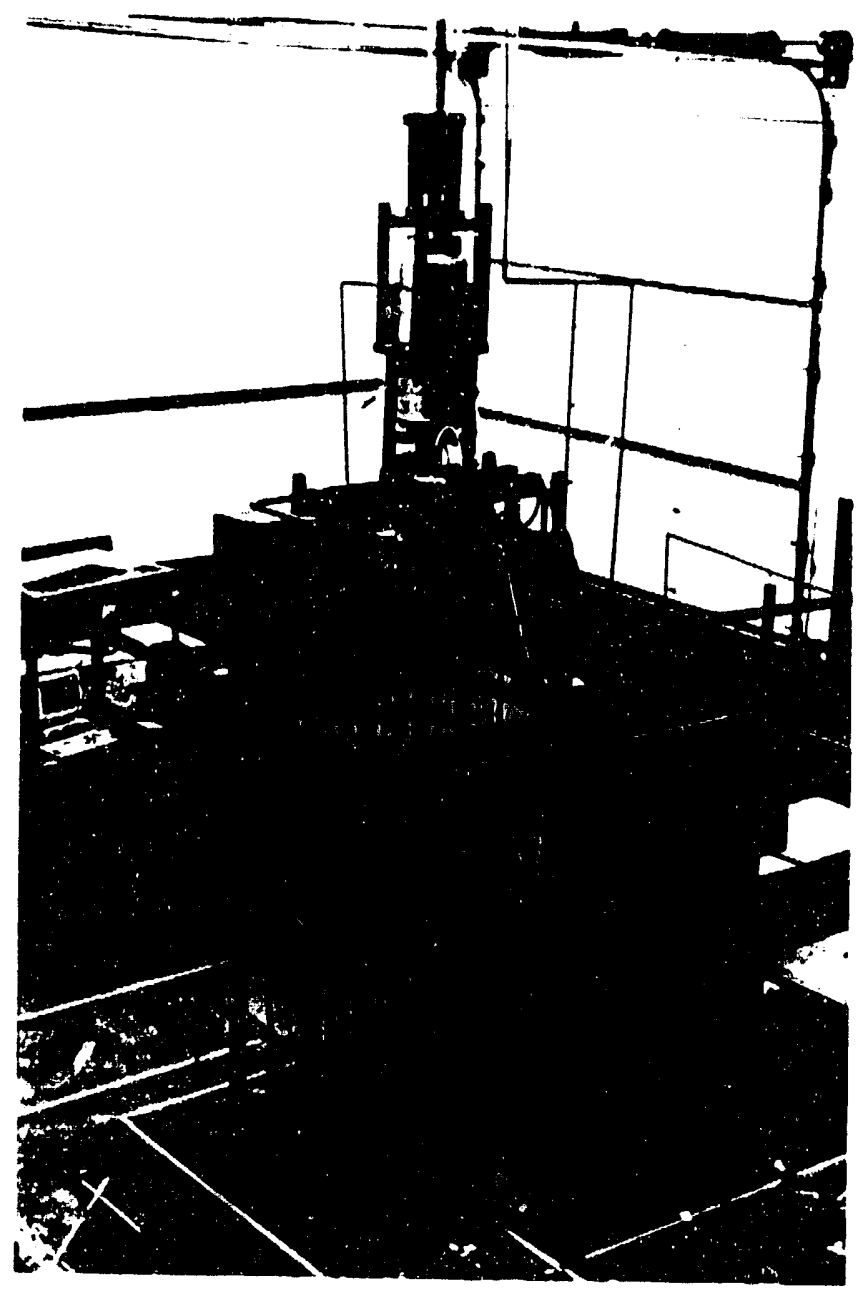

Figure 11 Photograph of Purdue CHF Experimental Facility 
was increased from $1.0 \mathrm{KW}$ to $3.5 \mathrm{KW}$ with an increment of $0.5 \mathrm{KW}$ for each run. The results of one test run is summarized below. Fig. 12 shows the flow rate into the test section vs. time for the range of heater power used. Notice the fluctuation in the flow rate into the test section which is caused by the boiling process. At higher heater power values the boiling becomes very violent and chugging becomes dominant, which is clearly indicated by the large amplitude of the oscillation in the flow rate signal. Fig. 13 shows the mean flow rate into the test section vs. the heater power. It is clear that the flow rate falls from the mean value of 35 $\mathrm{cm} / \mathrm{sec}$ to a much lower value at heater powers in access of $2.5 \mathrm{KW}$, which indicates the occurrence of the flow instability. The phenomena of chugging could be explained as follows: When boiling takes place in a closed channel, or loop, at relatively high rates, the vapor generated expands in the loop and causes the inlet fluid to decelerate. After the vapor has condensed, the pressure in the loop will drop and hence will cause the fluid to accelerate in the test section causing further rapid boiling which will again produces large amount of vapor, and so on.

Fig. 14 shows the inlet subcooling to the test section for three different values of heater power. Notice that the subcooling decreases with time. This was caused by the continuous running of the experiment. If constant subcooling is desired then time should be allowed between individual runs. Fig. 15 shows the temperature of the two-phase mixture coming out of the test section for the same runs reported in the previous figure.

Fig. 16 shows the pressure drop across the test section for two values of heater power. Notice the decrease in the mean pressure drop when boiling boiling occurs. This is mainly due to increase in the void fraction in the test section.

The photographs of the boiling in the test section are shown in Figs. 17-19 for different heater power. At heater power of $1.5 \mathrm{~kW}$ (Fig. 17) we observe a subcooled boiling. This is also evident from the outlet fluid temperature (Fig. 15). At heater power of $2.5 \mathrm{~kW}$ (Fig. 18) the we observe saturated boiling. At heater power of $3.5 \mathrm{~kW}$ (Fig. 19) there is vigorous boiling with large amount of vapor produced. The vapor bubbles coalesce and the flow regime is almost churn-turbulent. This region shows the occurence of instability as seen from the mass flow rate.

Currently the experiments are being carried out to study in detail the hydrodynamically induced flow instability and CHF for various system parametrs such as inlet subcooling, fluid flow rate, system power, system inlet and outlet restriction conditions. 


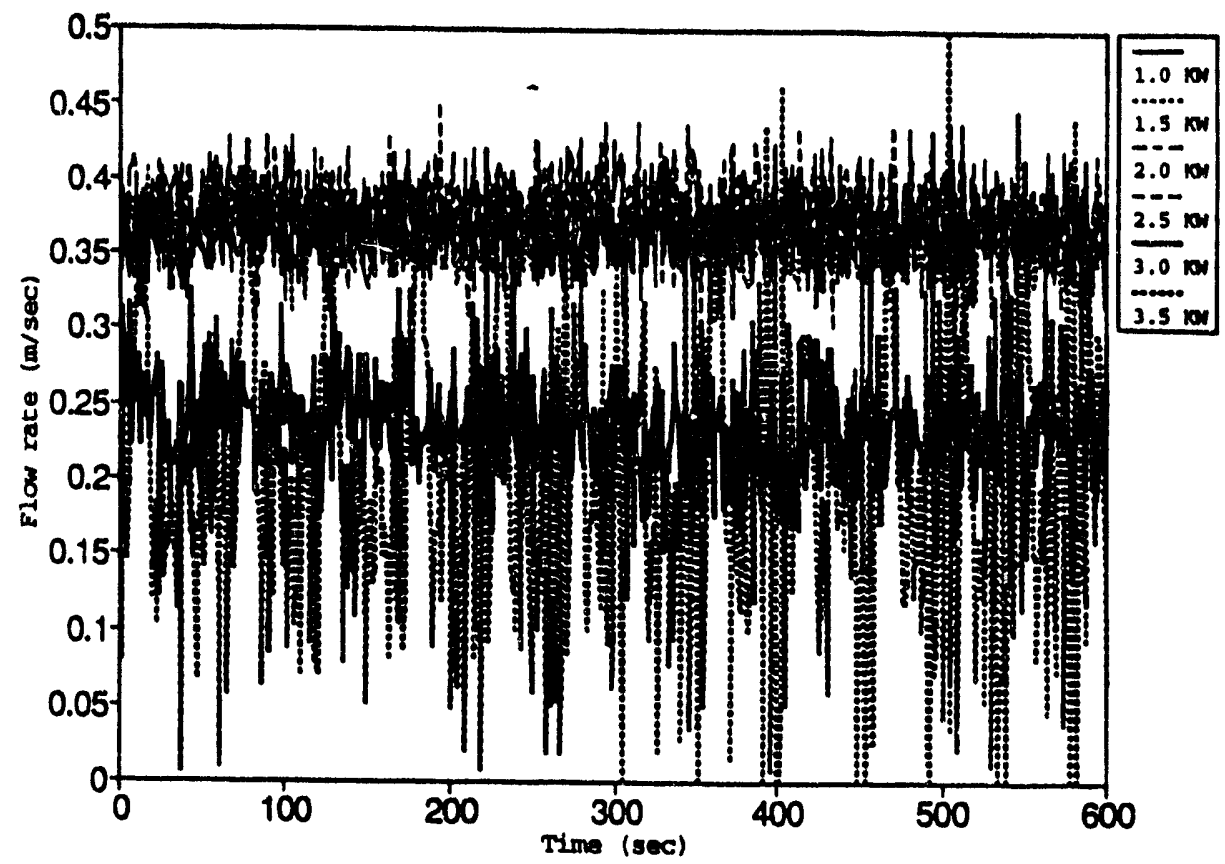

Figure 12 Test section flow rate vs. time for different heater powers

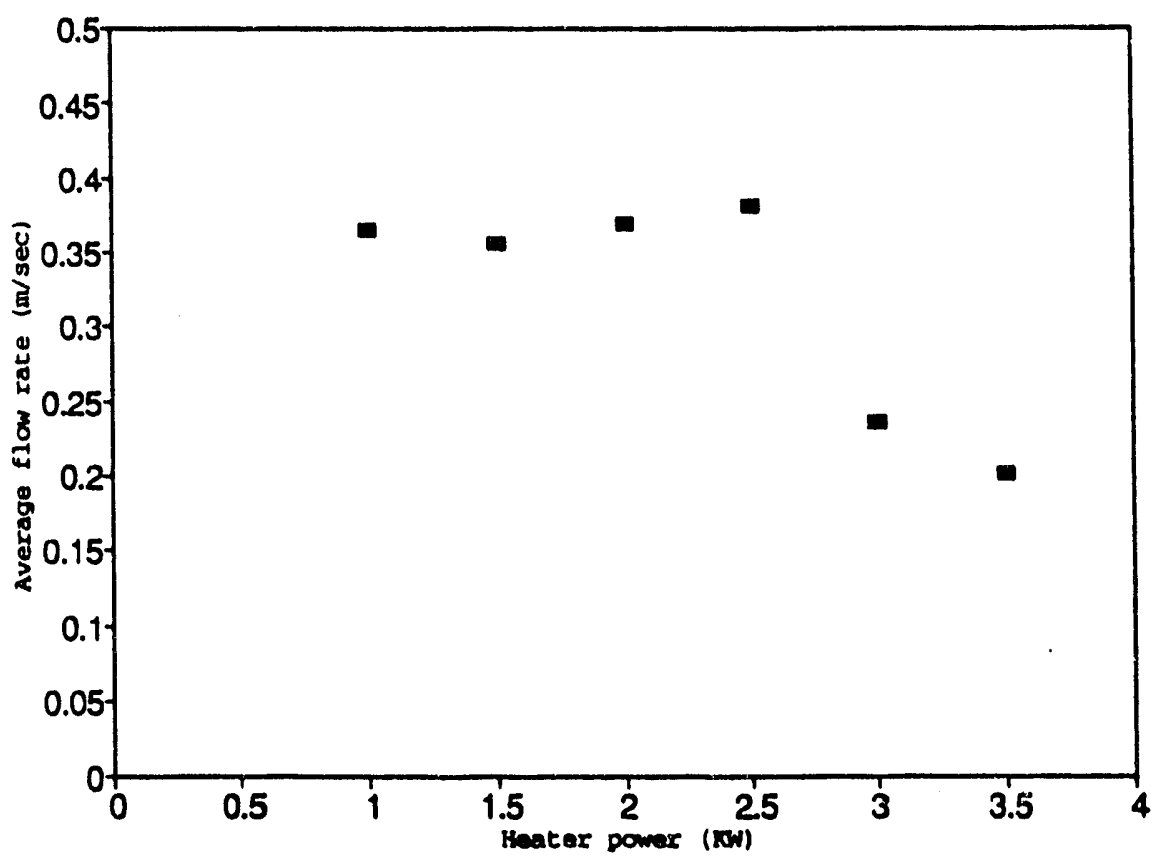

Figure 13 Test section mean flow rate vs. heater powers 


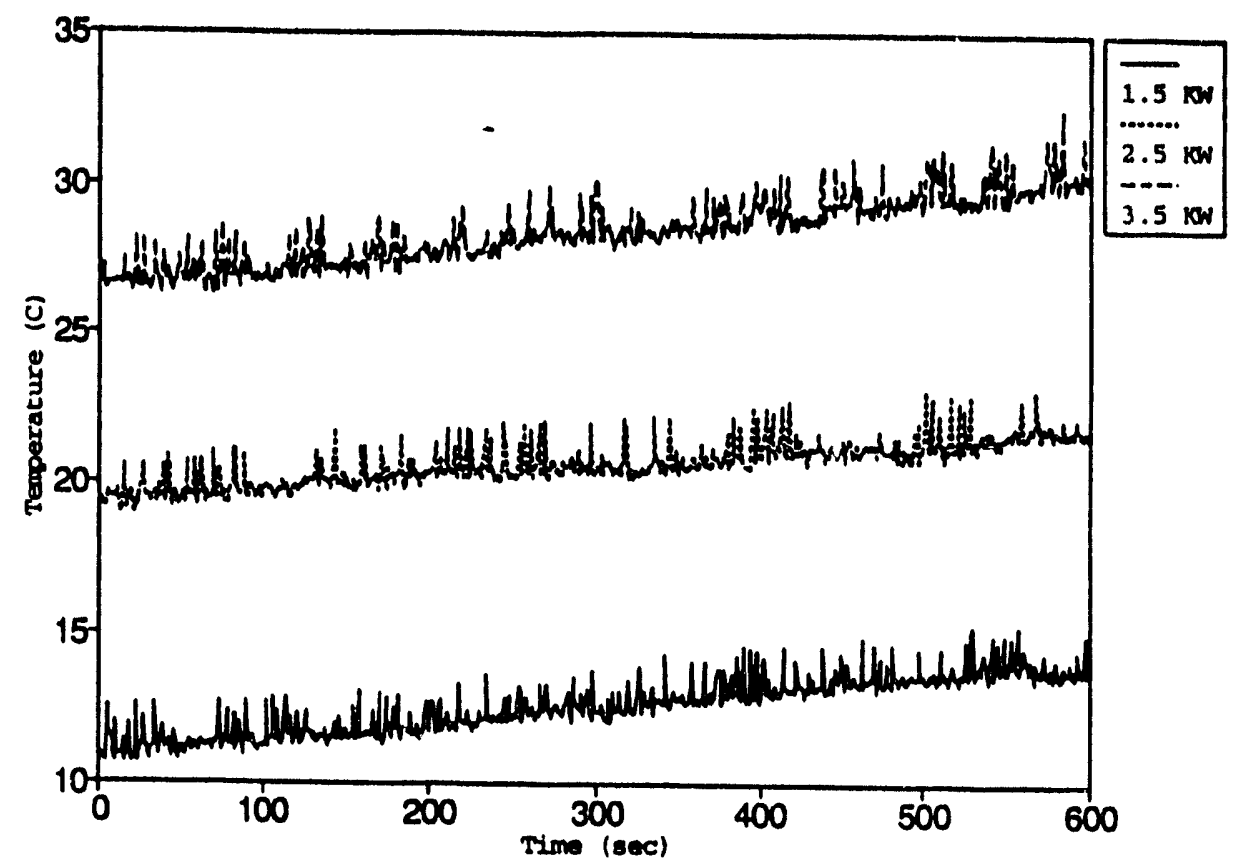

Figure 14 Inlet fluid temperature for different heater powers

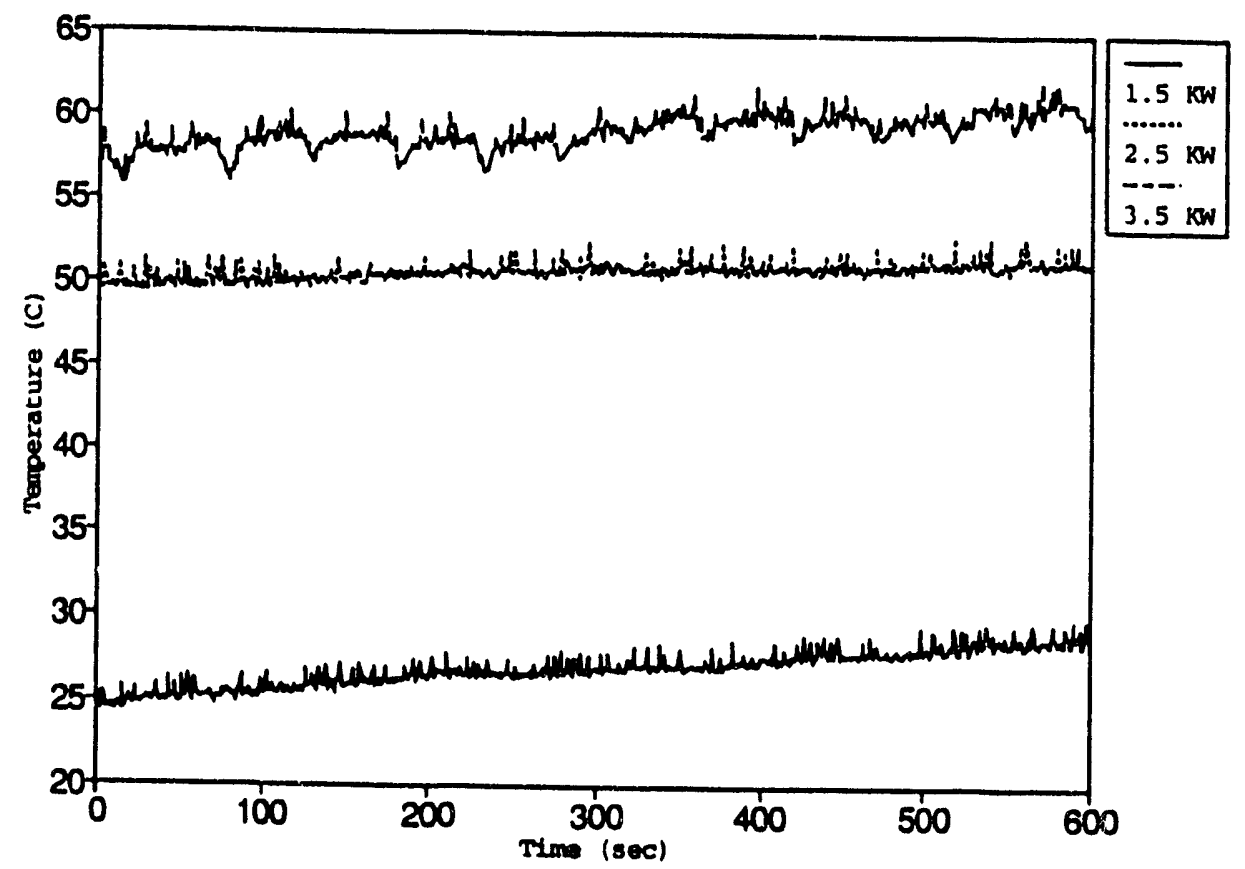

Figure 15 Outlet temperature of the fluid for different heater powers 


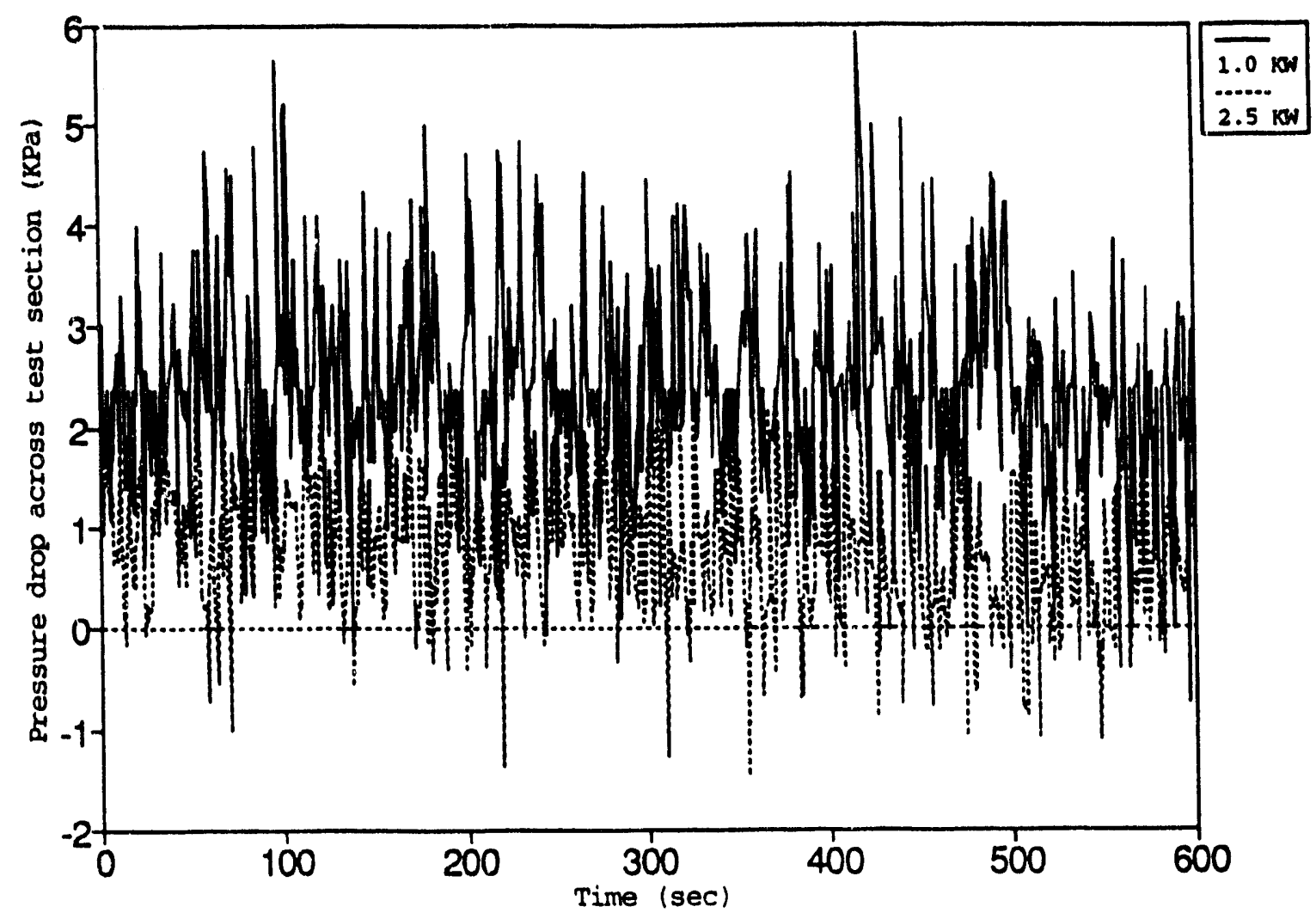

Figure 16 Pressure drop across the test section for different heater powers 


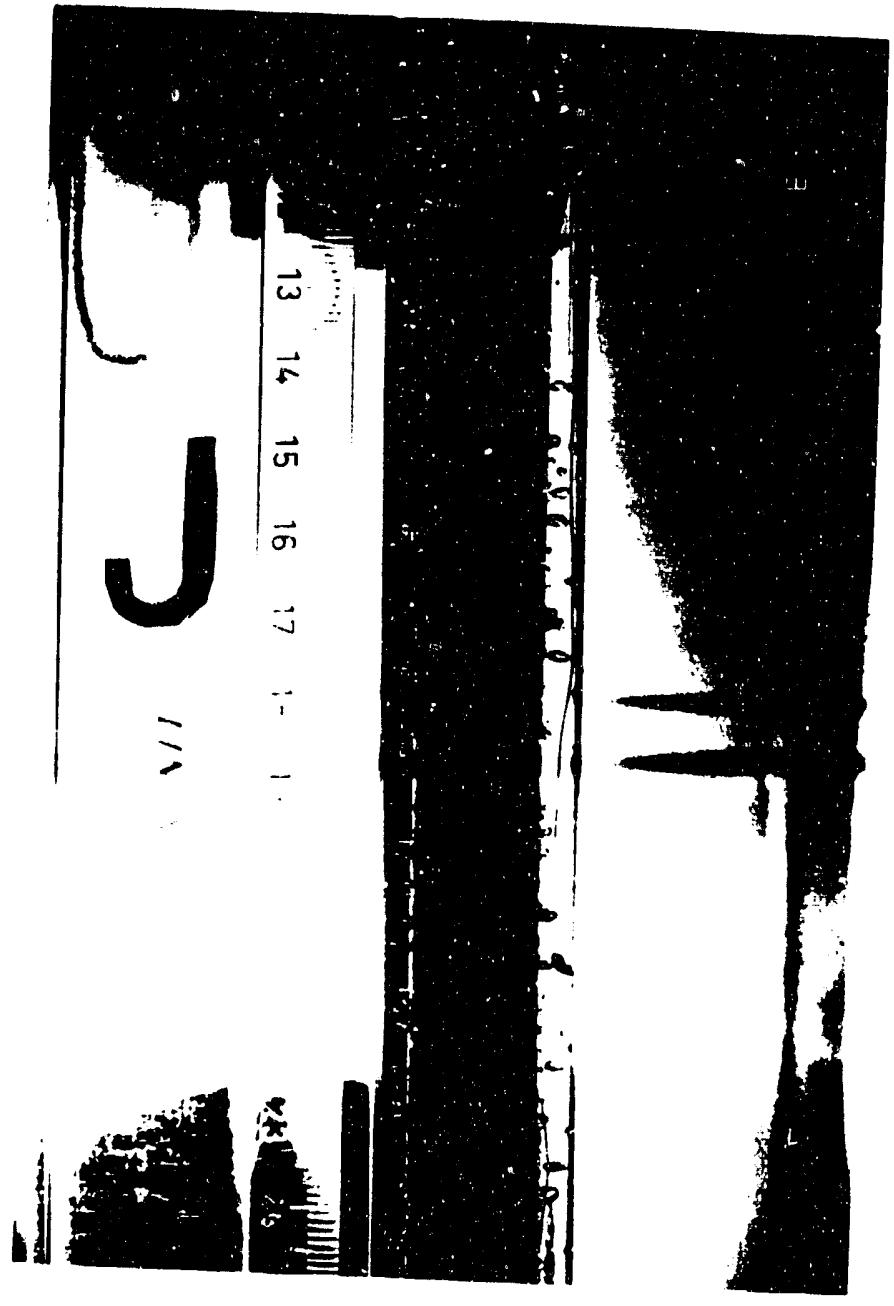

Figure 17 Photograph of the test section at liquid velocity of $35 \mathrm{~cm} / \mathrm{s}$, heater power of $1.5 \mathrm{~kW}$, and inlet subcooling $24 \mathrm{C}$ 


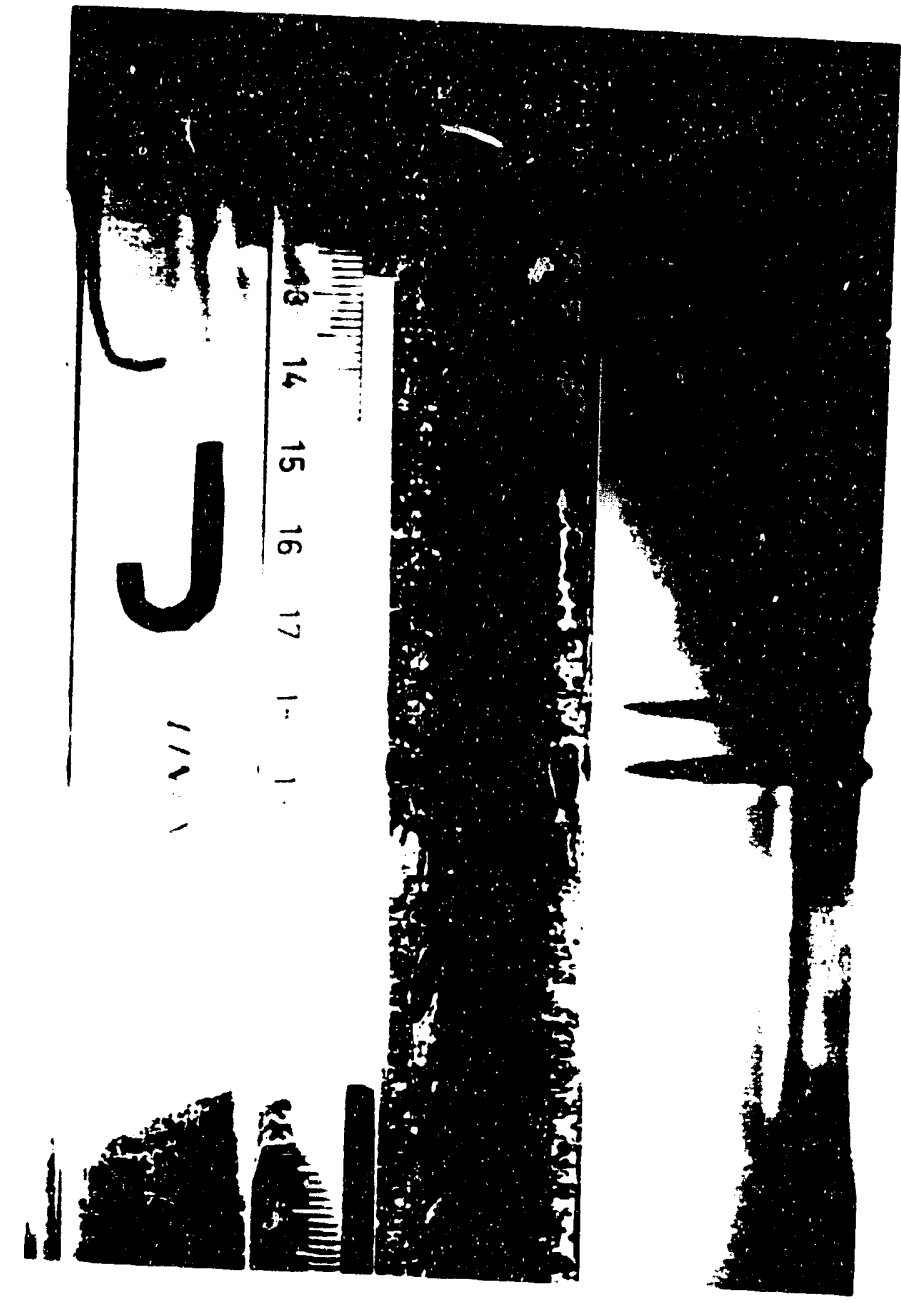

Figure 18 Photograph of the test section at liquid velocity of $25 \mathrm{~cm} / \mathrm{s}$, heater power of $2.5 \mathrm{~kW}$, and inlet subcooling $24 \mathrm{C}$ 


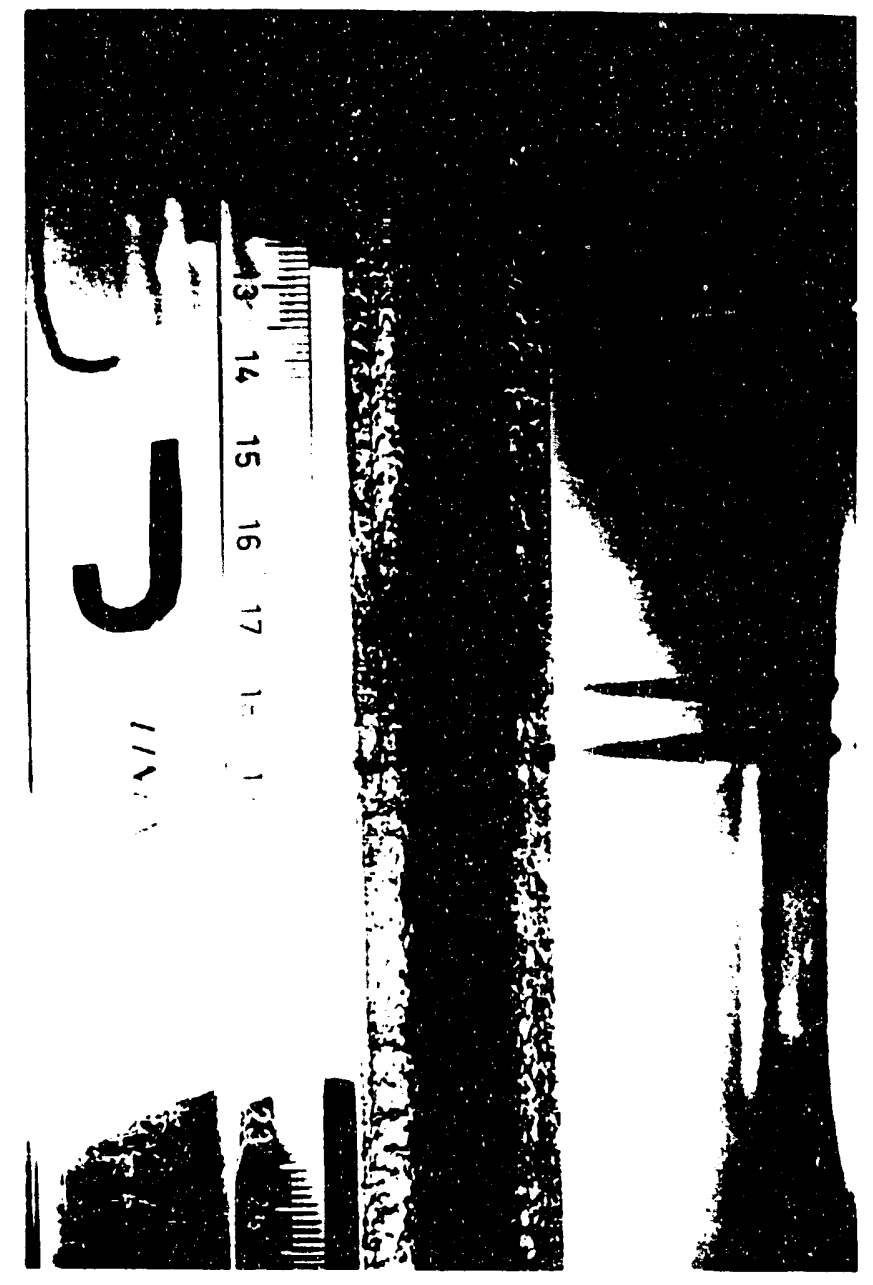

Figure 19 Photograph of the test section at liquid velocity of $20 \mathrm{~cm} / \mathrm{s}$, heater power of $3.5 \mathrm{~kW}$, and inlet subcooling $24 \mathrm{C}$ 


\section{POST CHF IN INVERTED FLOW}

Inverted annular flow, which consists of a liquid core surrounded by a vapor annulus, as shown in Fig. 20, is of considerable importance in the areas of confined, low quality film boiling applications such as LWR accident analysis. While many analytical and experimental heat transfer studies for this flow situation have been carried out, the relevant hydrodynamics of the post-CHF flow field received less attention. A more thorough understanding of the hydrodynamics of the post-CHF flow is necessary in order to adequately assess post-CHF heat transfer due to the coupled thermo-hydraulic nature of confined flow film boiling phenomena. Consequently, the determination and characterization of the various two-phase flow regimes both before and after CHF become important in determining beat transfer (as well and mass and momentum transfer).

A visual study of film boiling was carried out to determine the flow regime transition in the post-CHF region for a transient bottom reflooding of a hot transparent test section. The effect of test liquid subcooling and inlet velocity on flow transition as well as on the quench front propagation was investigated. The respective ranges for liquid velocity and subcooling were $1.8-26.8 \mathrm{~cm} / \mathrm{sec}$ and $20-45 \mathrm{C}$, respectively. The test liquid was Freon 113 which was introduced into the bottom of the quartz test section whose walls were maintained well above the film boiling temperature of the test liquid, via a transparent heat transfer fluid. The flow regimes observed down stream of the upward moving quench front were the rough wavy, the agitated, and the dispersed droplet/ligaments in agreement with a steady state, two-phase core injection study carried on recently by one of the authors. A correlation for the flow regime transition between the inverted annular and the dispersed droplet/ligament flow patterns was developed. The correlation showed a marked dependence on the void fraction at the CHF location and hence on the flow regime encountered in the pre-CHF region.

\subsection{State of the Arts Review}

Most of the research on the post-CHF region dealt mainly with heat transfer. Excellent reviews of the widespread literature were provided by Jordan[19] and Clemments and Clover[20]. A subsequent review by Kalinin et al.[21] considered both free and forced convective film boiling in great detail. Complete tabulations as well as extensive graphical comparisons of the various predictive equations for heat transfer were given. However, because heat transfer is significantly influenced by the regime of film boiling, some of the disagreement among the various correlations are not so readily explained due to insufficient understanding of the complex hydrodynamics of the post-CHF region[8].

Visual and high-speed motion picture observations of film boiling in channels have been reported by a number of researchers. For upward flow of liquid nitrogen in a vertical tube, 
DISPERSED

DROPLET

FLOW

INVERTED SLUG

OR

CHURN FLOW

INVERTED

ANNULAR

FLOW

TRANSITION BOILING

CHF OR DRYOUT

NUCLEATE BOILING

Figure 20 Possible flow regimes in post-CHF region 
Laverty and Rohsenow[22] obtained two distinct flow regimes: an inverted annular flow with liquid in the center and vapor in the annulus occurred at the beginning of the heated section, followed by a dispersed region of ligaments/droplets of liquids at greater tube lengths. In a subsequent study, Forslund and Rohsenow[23] confirmed the large departure from equilibrium in dispersed flow film boiling. A detailed review of visual studies in the postCHF region was reported oy Denten and Ishii[8]. A detailed experimental study of inverted annular flow for the adiabatic and diabatic cases were reported by Ishii and coworkers[7,24,25]. The disintegration of the liquid core into droplets was found to be due to two different mechanisms: wave instabilities at the interface and roll-wave entrainment. Correlations for core shape, breakup mechanisms and dispersed core drop size were developed for the adiabatic case, by extending the results of free jet instability, roll-wave entrainment and churn turbulent droplet stability studies. The diabatic study reported the presence of four well-defined flow regimes in the post-CHF region; namely, inverted annular, agitated, inveried slug/chum and dispersed flow regimes. The axial extent of each flow regime, as well as the transition from one regime to another, was found to depend markedly on the relative velocity between the gas and the liquid, in agreement with the observation of Laverty and Rohsenow[22]. Correlations were developed for the axial extent of flow regimes reported above.

A number of computer codes and analytical/empirical models have been developed for predictions of void fractions, wall temperatures and heat fluxes in the post-CHF region[11,26]. A review of the numerous analytical and empirical methods for annular and slug flow film boiling was carried out by Groeneveld[27], while Chen[28], in his review, examined phenomenological questions relevant to our understanding of the transport mechanisms in the post-CHF heat transfer. Yadigaroglu and Bensalem[29] presented a critical and thorough review of the various approaches that are used for modeling of interfacial mass generation in two-phase flows, including a detailed discussion of the mechanistic models for inverted annular and dispersed flow film boiling. More recently, Nelson and Unal[30] developed a heat transfer model for the post-CHF region based on flow transition criteria.

Ishii and Denten[8,31] extended the studies, reported by Ishii and co-workers[7,24,25], to investigate the axial extent and flow regime transition in an idealized inverted annular flow geometry where a two-phase liquid core is injected into the heated test section surrounded by a gas annulus. They correlated the axial extent of the agitated flow regime in the post-CHF region in terms of the two-phase liquid jet Capillary number, $\mathrm{Ca}=\frac{\mu_{\mathrm{f}} \mathrm{j}_{\mathrm{J}}}{\sigma}$, and the jet theoretical void fraction. Their correlation is given by:

$$
L / D=595 \sqrt{\mathrm{Ca}}\left[1-\frac{\alpha_{\mathrm{J}}}{0.854}\right]^{1.22}
$$


The brief review presented above indicates that more effort has been recently put into the study of hydrodynamics of the post-CHF region. However, it is evident that there is a need for an experimental data base, to be used for validation of heat transfer models, on the hydrodynamics of the post-CHF region in a transient reflooding case. This paper attempts to address the case of low pressure, low flow, transient bottom reflooding experiment, explain the hydrodynamic characteristics of the flow field downstream of a moving quench front, and develop a flow transition criterion for the agitated regime in the post-CHF region.

\subsection{Post CHF Experiment}

\subsubsection{Experimental Facility}

An experimental facility was previously constructed to study steady-state film boiling of liquid Freon 113 in a transparent quartz tube test section. The inlet of this section was modified to run transient experiments, where a quench front is allowed to propagate downstream in the test section, with measurable inlet flow conditions at the heated test section entrance. Since a very elaborate description of the experimental apparatus is given elsewhere[32,33], the following is a brief summary of the modified experimental facility.

A schematic of the modified film boiling facility is shown in Fig. 21. With the arrangement shown, transient post-CHF flow field could be established in the test section. The heated portion of the test section, $1.0 \mathrm{~m}$ in length, consists of two coaxial quartz tubes (see Fig. 22). The dimensions of the inner and outer quartz tubes were $18 / 15 \mathrm{~mm}$ OD/ID and $35 / 31 \mathrm{~mm}$ OD/ID, respectively, giving an annular gap of $17 \mathrm{~mm}$ through which a hightemperature heat transfer fluid (Syltherm 800 by Dow Corning) was circulated. The inner quartz tube extended beyond the outer quartz tube to provide an unheated entrance length of $15 \mathrm{~cm}$. Core liquid flow rates were measured with a turbine flow meter. Pressure taps were located in the piping at the start of the unheated length of the inlet quartz tubing and in the piping at the outlet of the heated portion of the test section. Chromel-alumel thermocouples were inserted in the flow stream at the same locations as the above-mentioned pressure taps, and were also inserted into the flow of heat transfer fluid entering and leaving the heated portion of the test section.

Post-CHF conditions could be established in the test section by heating the heat transfer fluid above minimum film boiling temperature and then introducing the test fluid into the inner quartz tube directly. The drawback with this approach is one of lack of control of the annular vapor flow conditions. This difficulty was overcome in the previous experiments by establishing an idealized geometry where a gas annular jet is injected into the test section simulating the vapor annulus that surrounds the liquid core in the case of inverted annular flow. This geometry was, however, abandoned in this experimental study for the purpose of investigating the hydrodynamics of the transient flow field downstream of a quench front. Photographic observation of the post-CHF-hydrodynamic behavior within the heated test 


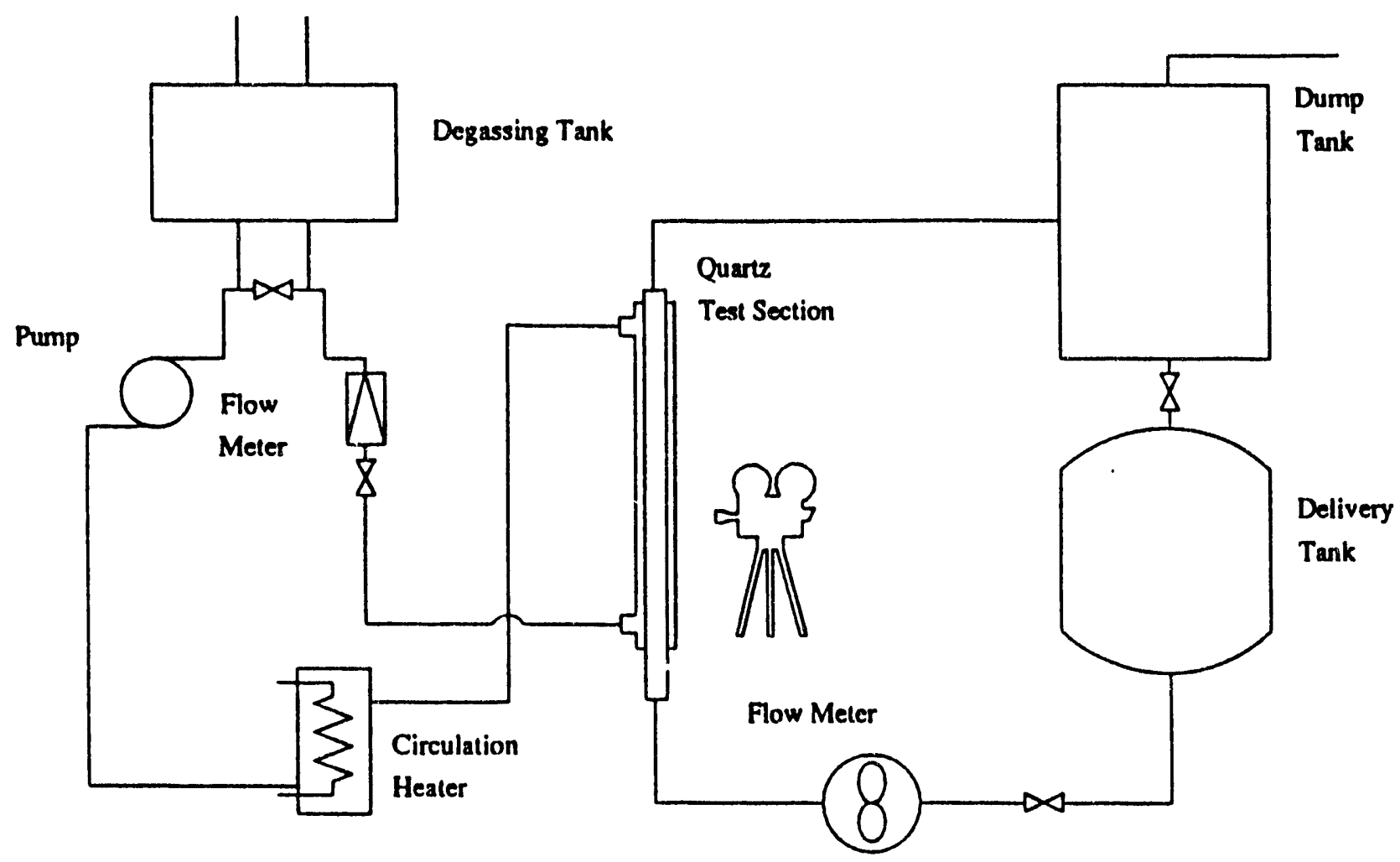

Figure 21 Schematic drawing of test rig

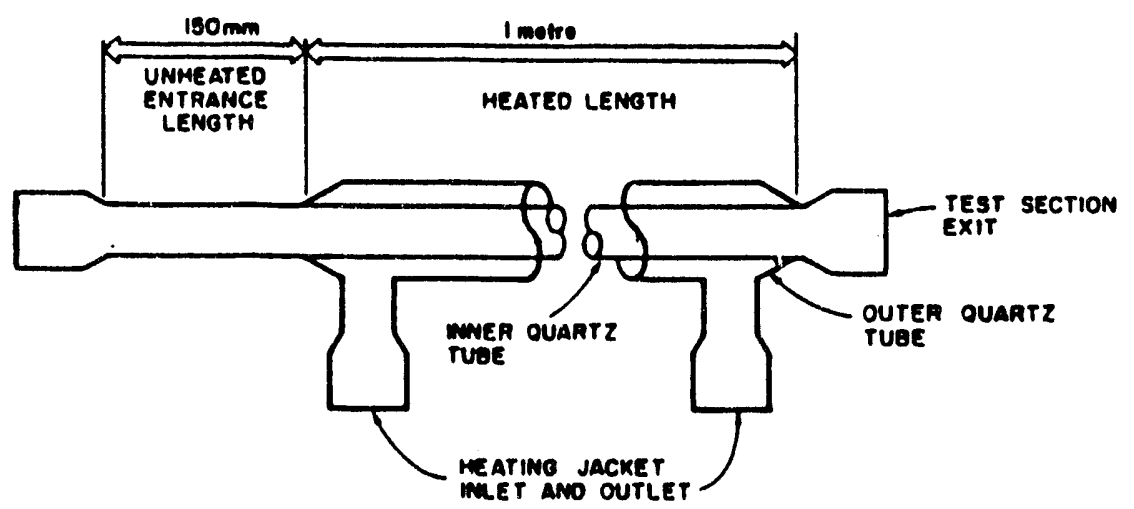

Figure 22 Quartz test section 
section was accomplished using still photography. Motion pictures were taken to record the speed of propagation of the quench front in the test section. Lighting for the still photography was provided by a $3 \mu \mathrm{s}$ strobe lights delivering a $0.5 \mathrm{w}$-s pulse of light bounced off a white background and onto the test section. A transparent ruler, marked in $1 \mathrm{~cm}$ increments (beginning with zero at the test section inlet) was fixed along the side of the test section. This ruler gave ready reference to the axial position along the heated test section.

\subsubsection{Experimental Parameters}

Essential variables in this e:perimental study were the jet core liquid flow rate and the subcooling of the inlet core. The ranges of the flow parameters are given below:

$\begin{array}{lc}\text { Flow parameter } & \text { Range } \\ \text { Inlet velocity } & 1.8-26.8 \mathrm{~cm} / \mathrm{sec} \\ \text { Inlet subcooling } & 20-45 \mathrm{C}\end{array}$

\subsection{Experimental Observations}

In this section an overview of the hydrodynamics of the post-CHF flow field is given. Graphical data for flow regime axial extent are also presented. Due to its dominance in the flow field, emphasis in the analysis is placed on the transition flow pattern between inverted annular and dispersed /igament droplet flow (agitated regime). Still photographs taken with black and white films were analyzed by placing the developed negatives in a slide projector. Initially, general flow field observations were made. Then a more careful and detailed analysis generated data on the axial extent of the various flow regimes present, using the image of the transparent ruler mounted alongside the test section as a reference. Motion pictures of the quench front propagation were analyzed using a VCR with a frame-by-frame advancing capability. Details of the experimental methods and analysis can be found in [33].

\subsubsection{Hydrodynamic Behavior of the Post-CHF Flow Field}

In the present film boiling experimental study, the post-CHF flow regimes were similar to the flow patterns established previously by Ishii and Denten[31]. For single-phase liquid core injection, in the steady-state experiment, the post-CHF flow field contained four basic fow regimes: the smooth regime (stable inverted annular flow), the rough wavy regime, the agitated regime (transition flow between inverted annular and dispersed droplet flow), and the dispersed ligament/droplet regime[25]. For two-phase core injection, flow patterns resembling the rough wavy regime and the transition between inverted annular and dispersed droplet flow (the agitated regime), along with the dispersed ligament/droplet regime were observed[8]. The flow regimes observed in this experimental study are generally similar to the flow 
regimes observed for the steady-state, two-phase core injection experiment. In what follows we describe, briefly, the flow regimes encountered in the flow field downstream of the moving quench front.

\section{a) Rough wavy regime}

The rough wavy regime, or inverted annular flow preliminary break down, is present only for pre-CHF bubbly flow upstream of the quench front. The dominant features of the rough wavy regime are the presence of a fairly stable, intact liquid plus vapor central core, along with a very rough annular vapor-core liquid interface. Small vapor bubbles can be seen inside the two-phase core, Fig. 23, while small disturbances on the surface of the core quickly grow to large amplitude roll waves. Shearing and entrainment of core liquid from roll wave crests result in a reduced diameter core, along with fine structure liquid entrainment masses at the end of the rough wavy/beginning of the agitated flow regime. The axial extent of the rough wavy regime tends to increase gradually with increase in liquid inlet flow rate and, to a lesser degree, with subcooling.

\section{b) Agitated regime}

The agitated regime, which includes the inverted slug-churn flow field, is present for all pre-CHF flow regimes (bubbly, slug, and annular) upstream of the quench front. The agitated regime constitutes the unstable transition flow pattern between inverted annular flow film boiling and dispersed ligament/droplet flow, Fig. 24. The dominant features of the agitated regime are the presence of thin, very fine structure skirt-like annular liquid sheets and small droplet clouds close to the heated wall.

\section{c) Dispersed droplet/ligament regime}

The dispersed droplet/ligament regime is present for all types of pre-CHF flow (bubbly, slug, and annular) upstream of the quench front. Beginning at the downstream edge of the agitated regime, the dispersed flow pattern extends to the test section exit for all trials in this experimental study. The dominant feature of this flow regime is the presence of fairly homogeneous dispersed liquid droplets and small ligaments, Fig. 25.

\subsubsection{Agitated Liquid Entrainment mass}

The distinct feature of the agitated flow regime is the presence of agitated liquid entrainment masses of annular shape that travel at a relatively high speed in a close proximity to the heated wall. The large interfacial area and the high speed at which the agitated entrainment masses travel suggest large heat and momentum transfer rates. De Jarlais and Ishii[32] provided an explanation of the formation mechanism of this type of entrainment masses. 


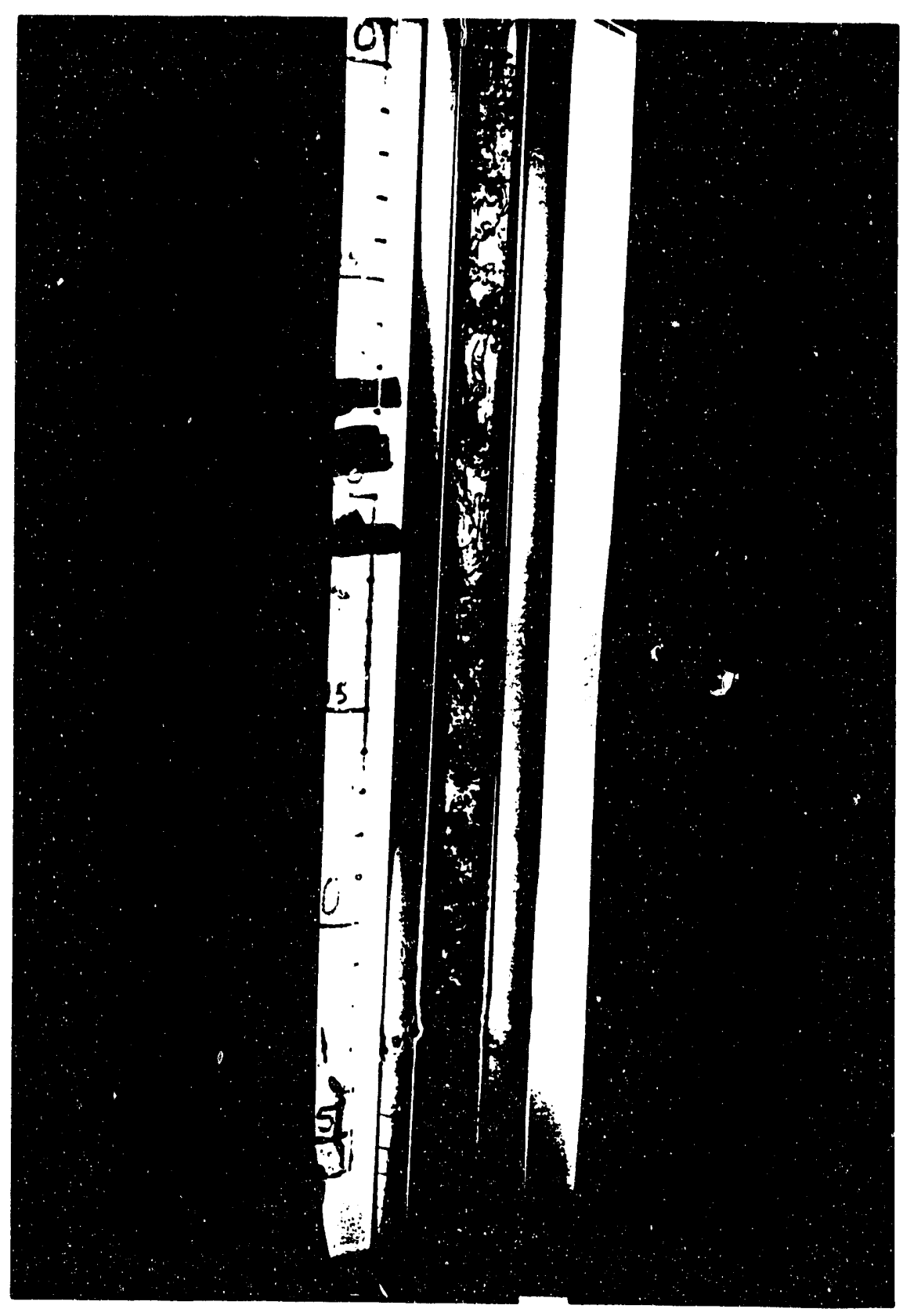

Figure 23 Photograph of post-CHF flow illustrating rough wavy regime 


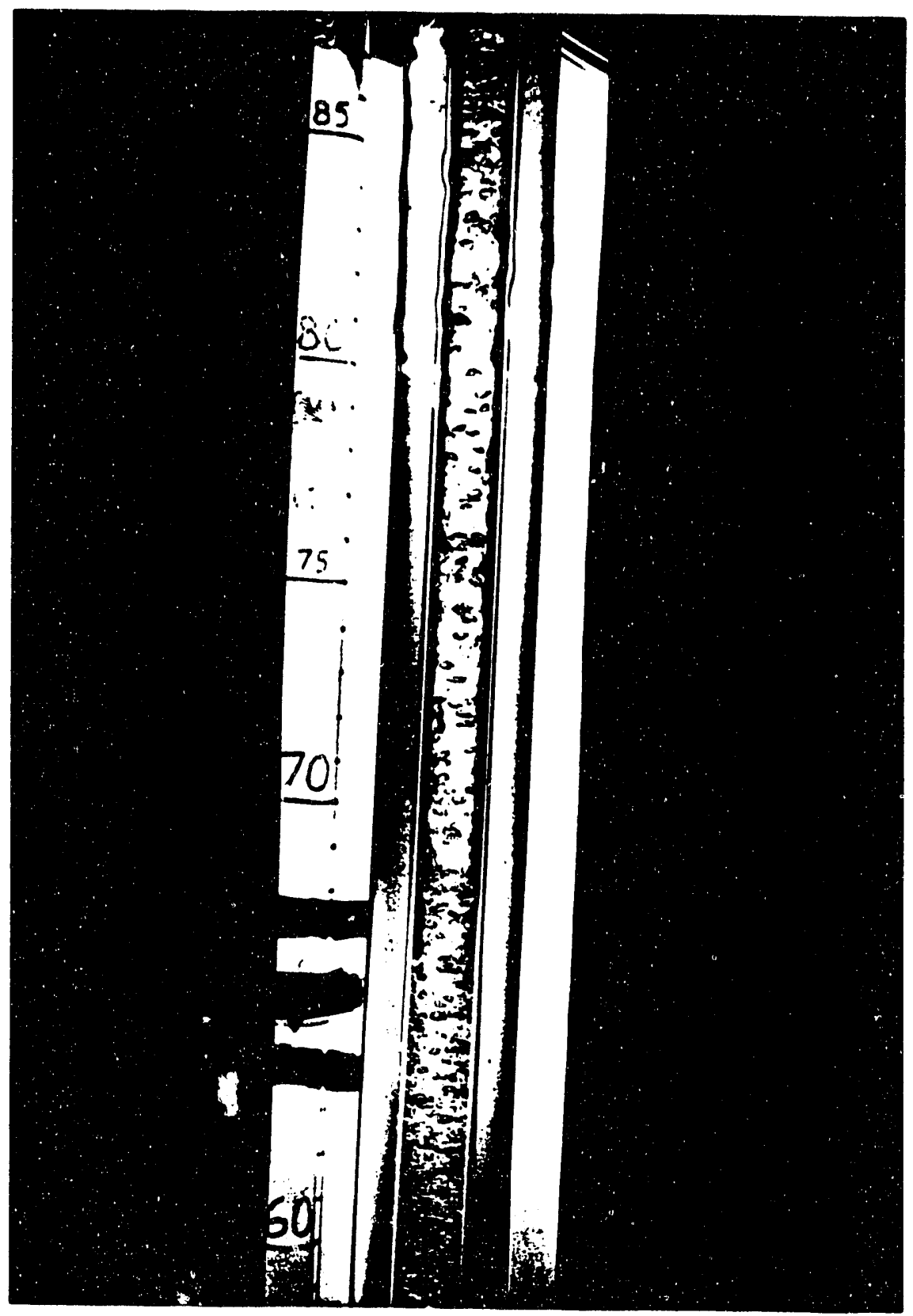

Figure 24 Photograph of post-CHF flow illustrating agitated regime 


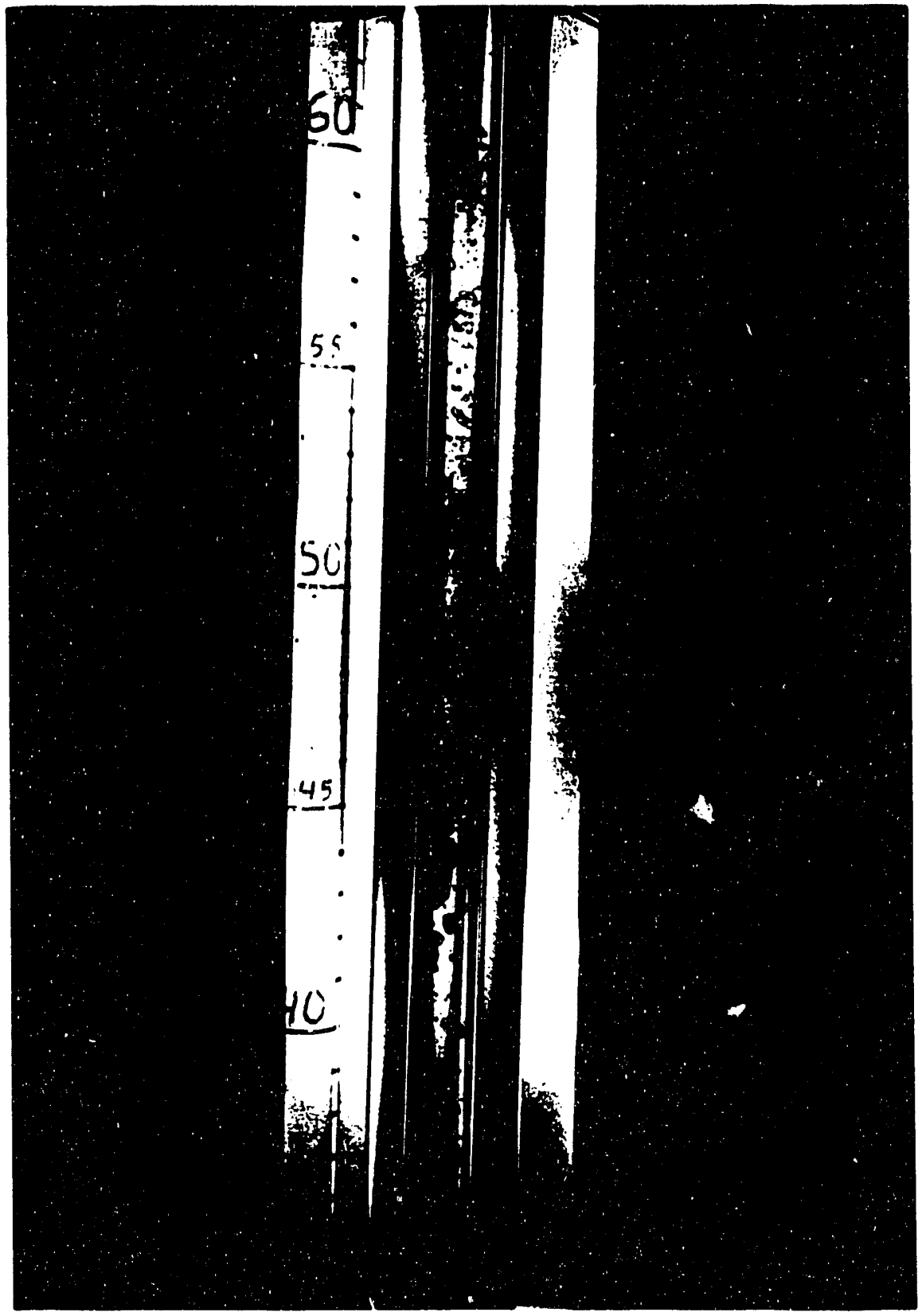

Figure 25 Photograph of post-CHF flow illustrating dispersed droplet/ligament regime 
As the roll wave disturbances grow in amplitude and volume, their large surface area per volume results in their rapid acceleration by the vapor annulus stream. As a result, liquid is pulled away from the liquid core. This accelerated liquid, as sheet-like expanded and distorted roll waves and as droplets sheared form $\mathrm{r}$ " wave crests, forms a thin, highly agitated annulus of liquid in close proximity to the heated wall, Fig. 26. As this agitated annular structure moves downstream, it depletes the liquid core, reducing it in diameter, while itself losing mass, from evaporation and from droplets shearing-off and ascelerating downstream faster than the bulk of the agitated region. When this liquid which has been formed and ejected from the agitated region has progressed downstream far from its point of

original occurrence, it becomes less coherent. Gaps can be seen in the once-uniform sheet, and is not in continual, close proximity of the heated wall. Eventually this annular sheet of liquid degrades into droplets and small ligaments.

\subsubsection{Quench Front Propagation}

The quench front propagation, shown in Fig. 27 is relatively slow compared to the Freon inlet velocity, hence the quisi-steady nature of this experiment. The fluid residence time in the test section is very small compared to the time it takes the quenching front to propagate downstream to the outlet of the test section. Notice that the quench front propagation is almost independent of the Freon inlet velocity for this specific test section. Isolated quenching spots were observed to form at higher Freon inlet velocity and were observed to propagate downstream into the test section. Eventually the main quench front will merge with the isolated quench spots resulting in an apparent jump in the propagation of the original quench front. It is thought that precursory cooling is causing the formation of the isolated quenching spots.

\subsubsection{Axial Extent of Agitated Flow Regime}

Dimensional plots for the axial extent of the agitated flow regime versus the inlet Freon velocity are given in Figs. 28-30. The first plot is for pre-CHF bubbly flow regime, the second is for pre-CHF slug flow regime, and the third is for pre-CHF annular flow regime. The axial extent data for these plots were obtained by visual analysis of the still photographs taken with a 55-mm lens (35-cm field view). Several general trends are apparent in Figs. 28-30. The increase in Freon inlet velocity results in a gradual increase in the axial extent of the agitated flow regime. Subcooling has a little, if any, effect on the axial extent of the agitated flow regime since the temperature at the CHF location is similar for similar wall temperatures. It is noted that the axial extent of the agitated flow regime observed in this experimental study is less than the axial extent for the steady-state two-phase core injection experimenti8].

\subsubsection{Correlation for Axial Extent of Agitated Regime}




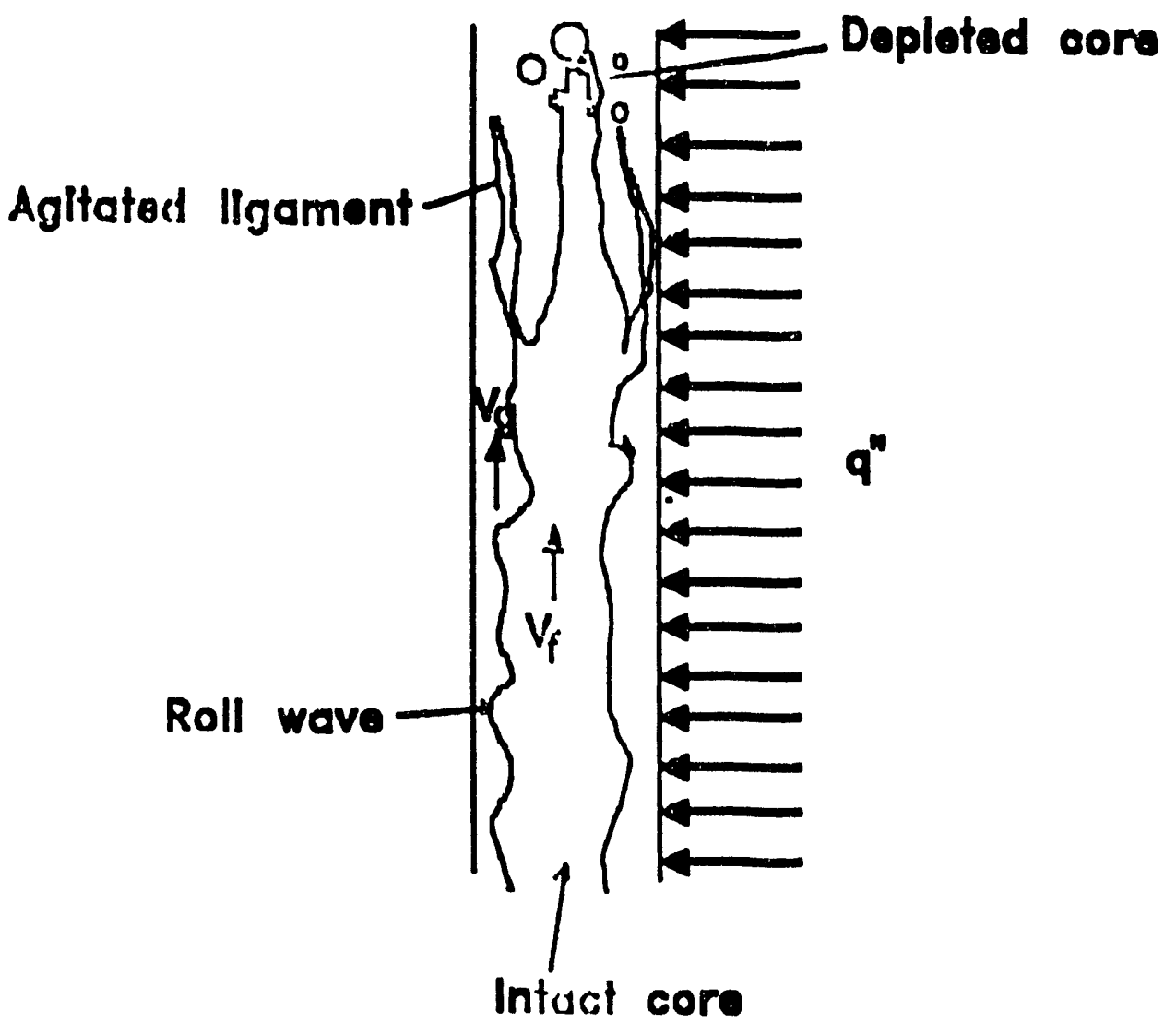

Figure 26 Formation mechanism of agitated mass 


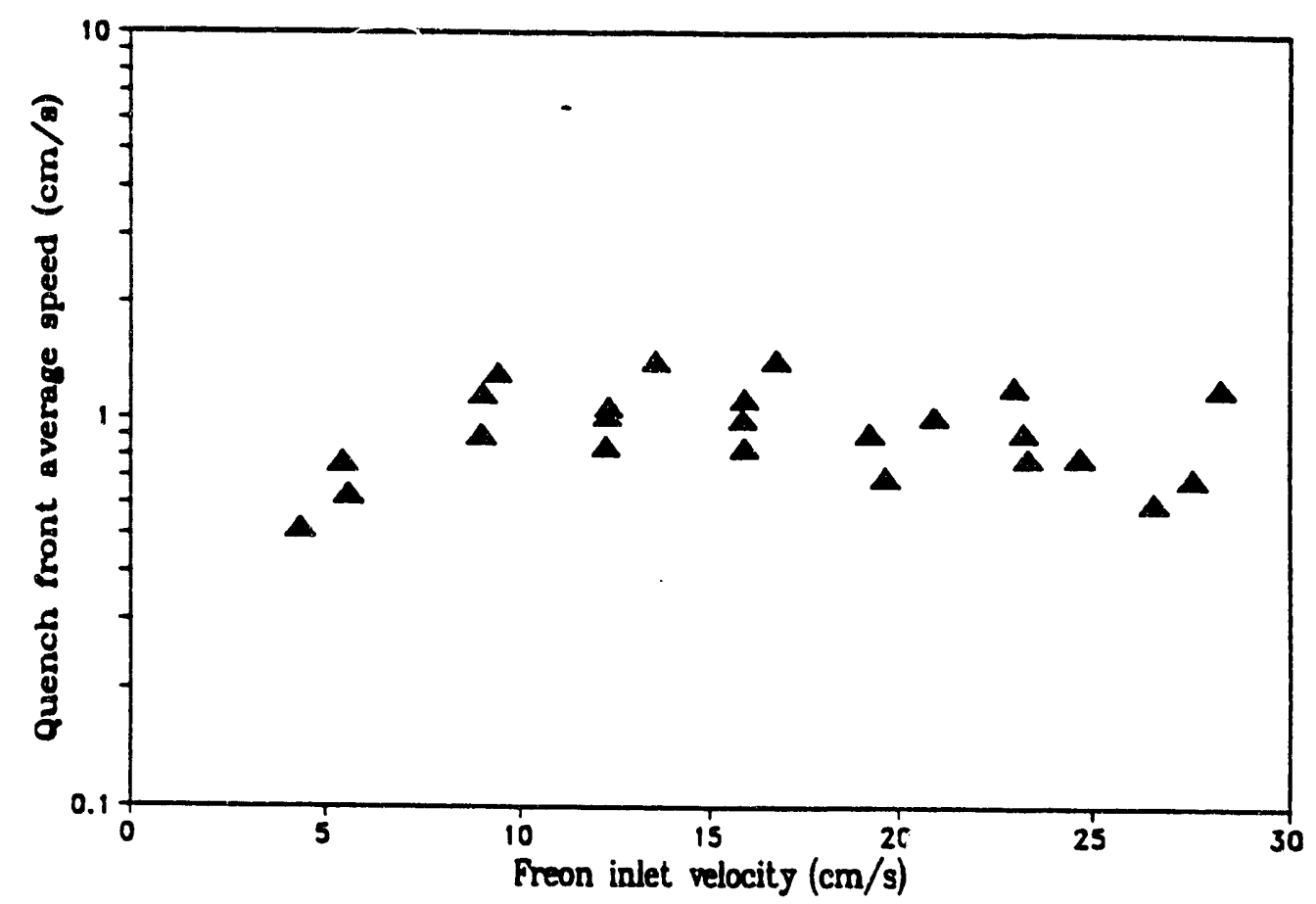

Figure 27 Propagation speed of quench front

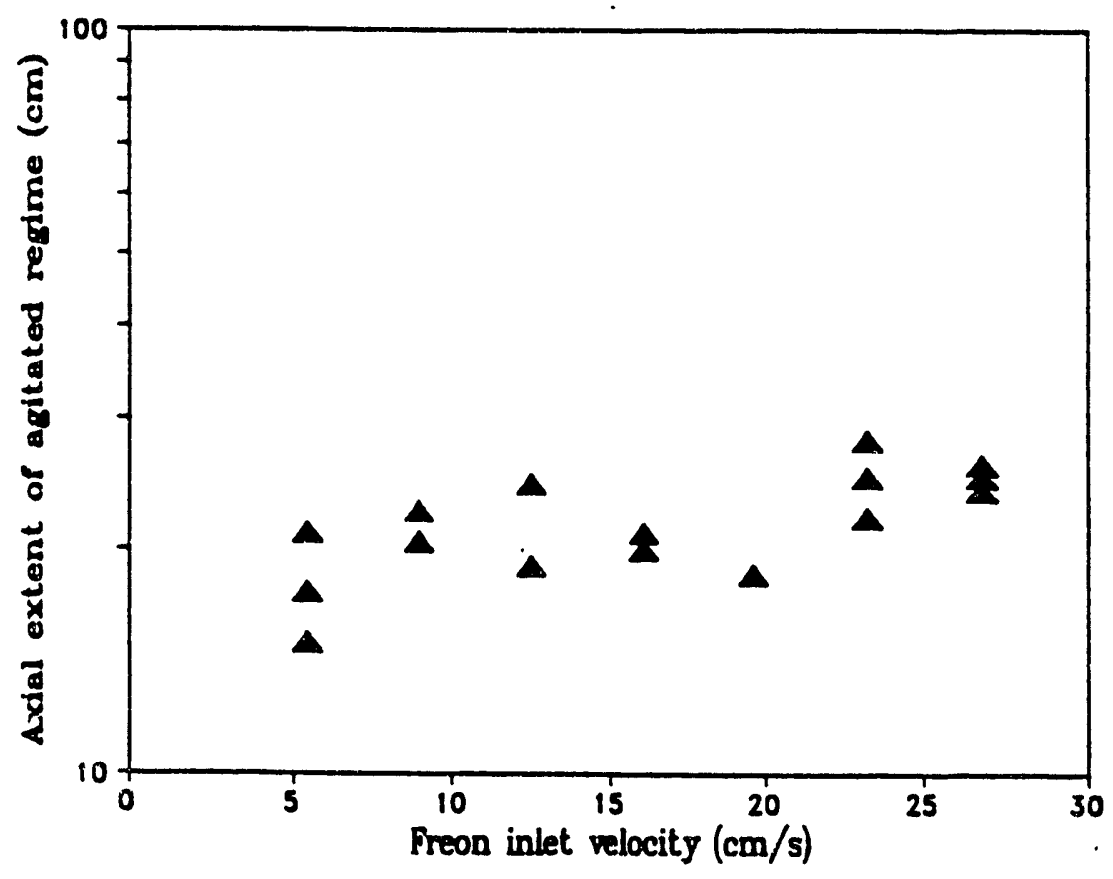

Figure 28 Axial extent of agitated regime - pre-CHF bubbly flow 


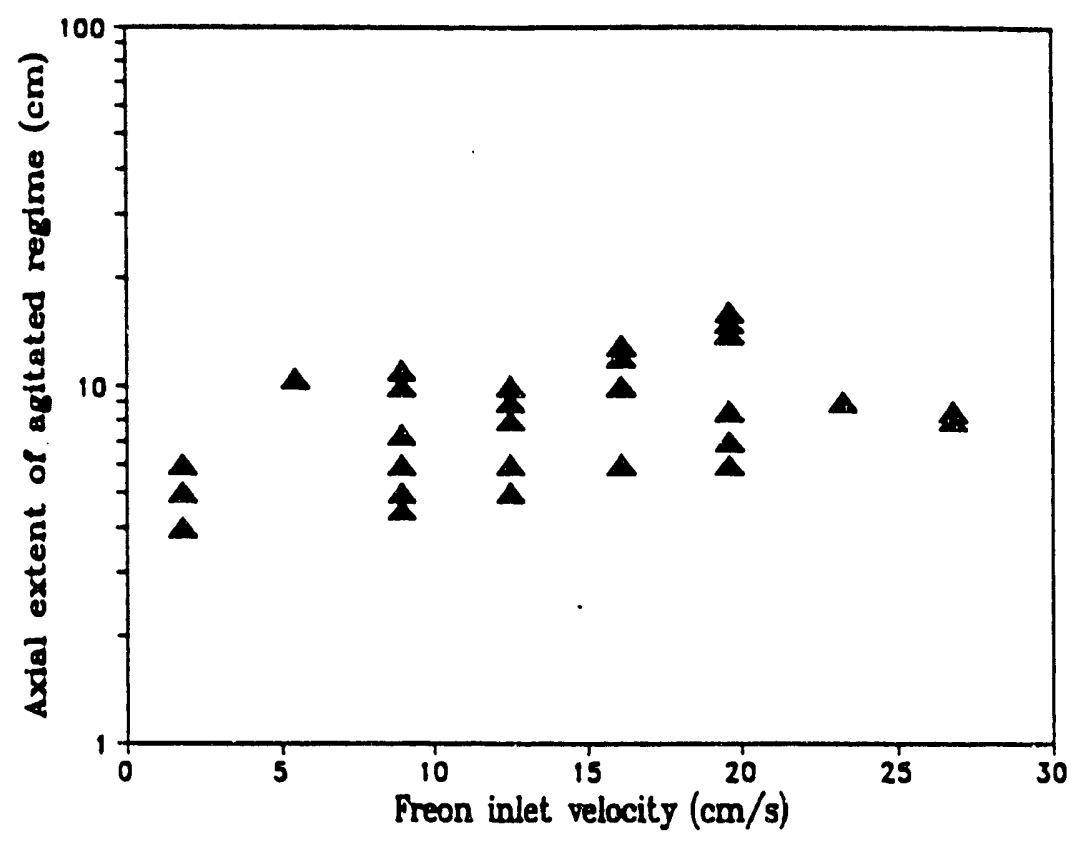

Figure 29 Axial extent of agitated regime-pre-CHF slug flow

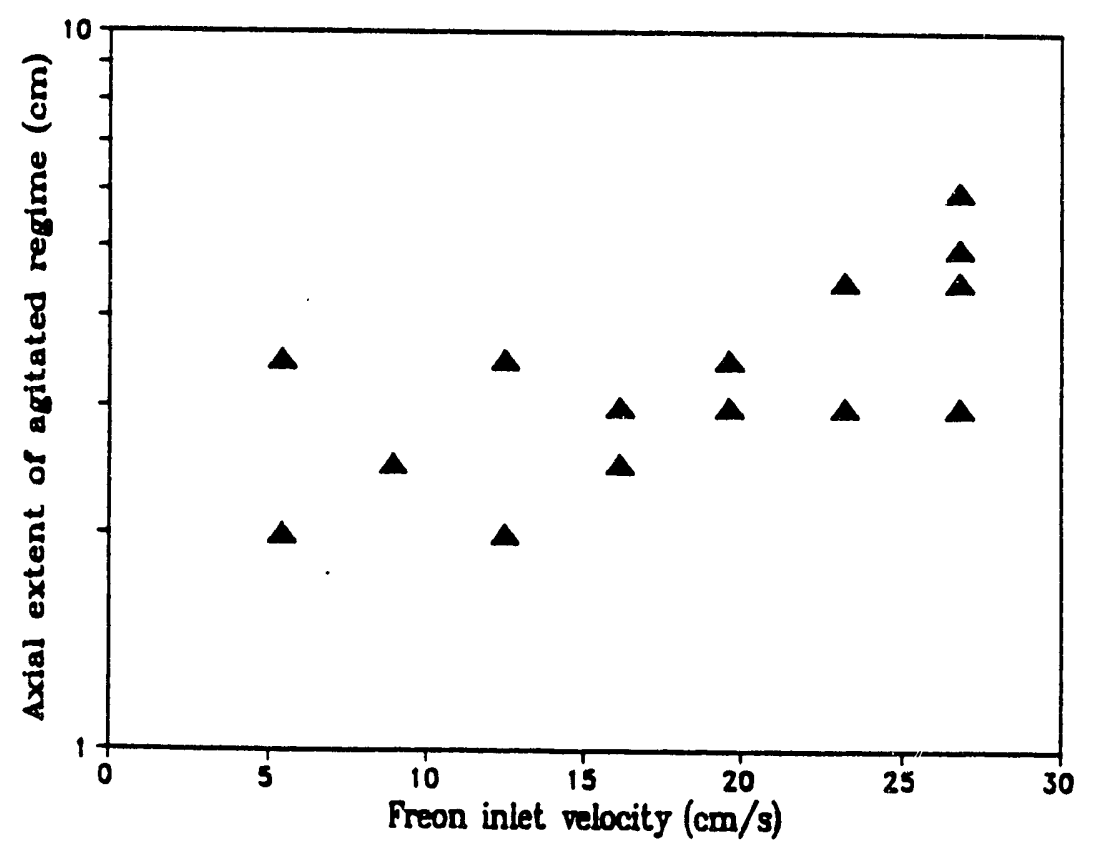

Figure 30 Axial extent of agitated regime - pre-CHF annular flow 
To maintain continuity with the steady state, two-phase, core injection study, a correlation of the following form is proposed:

$$
\mathrm{L} / \mathrm{D}=595 \sqrt{\mathrm{Ca}} \mathrm{f}
$$

where $f$ is a correction factor. The axial extent of the agitated flow regime, scaled with the mixture Capillary number and the liquid core diameter, is plotted in Fig. 31. The solid line in Fig. 31 represents the correction factor obtained from the experimental data points while the dotted line represents the correction factor reported by Ishii and Denten[23]. The correction factor for the present set of data is given by the following relation:

$$
\left[1-\frac{\alpha_{\mathrm{J}}}{0.854}\right]^{2.25}
$$

Fig. 31 shows the strong dependence of the axial extent of the agitated flow regime on the void fraction at the CHF location and hence on the flow regimes in the pre-CHF region. A comment should be made here concerning the plot of the correction factor $f$ in Fig. 31. At lower void fraction, at the CHF location, the curve of $f$ represents the upper bound of the axial extent, whereas at higher void fractions, the curve is merely an average value of the experimental data points. Since only still photography was used to determine the axial extent of the agitated regime. the axial extent for lower void fraction values, i.e. higher values of dimensional extent, captured in the photographs is not always the true axial extent, for the liquid core may extend further after shooting the picture. However, for higher void fraction values, i.e. lower values of dimensional extent, the axial extent captured in the photographs is much closer to its final value.

\subsection{Concluding Remarks}

A visualization study of film boiling during transient quenching, by introducing Freon 113 into the bottom of a heated quartz test section, was carried out. It has been established that the axial flow pattern in this study consists basically of three regions, namely, rough wavy, agitated, and dispersed droplet/ligament, in agreement with the flow field observed in the steady-state, two-phase core injection experiment[31].

The most significant of the above-mentioned flow regimes, as far as the analysis of postCHF heat transfer is concerned, is perhaps the agitated regime. The large interfacial surface generated in the agitated region indicates large heat and momentum transfer rates. Large momentum transfer is manifested in the periodic formation and acceleration of thin, highly agitated liquid entrainment masses. The fine structure and large interfacial area of these agitated entrainment masses indicate high heat transfer as these annular mass structures accelerate up the test section in close proximity to the heated wall. 


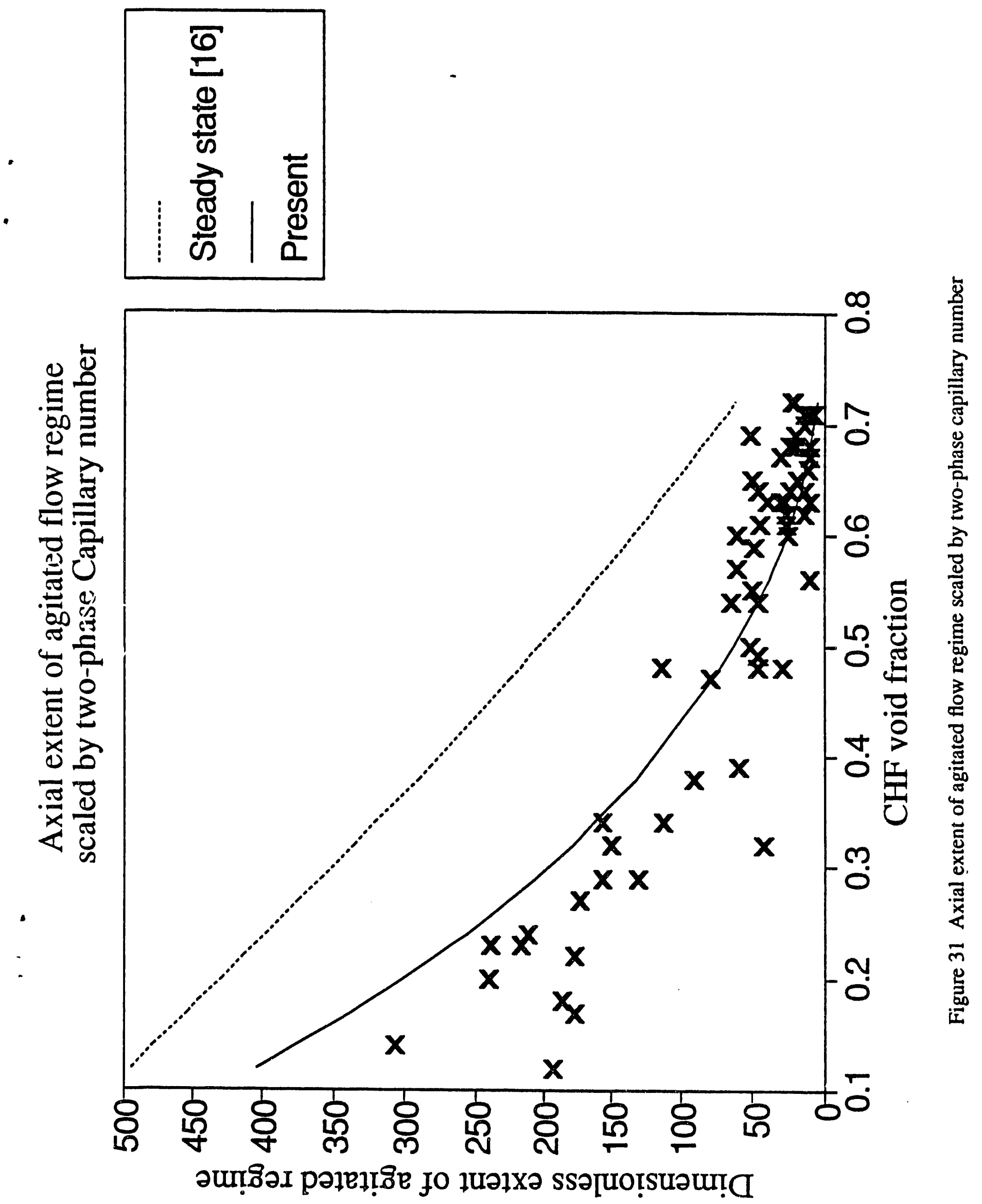


The low propagation speed of the quench front indicates that the current experimental study could be considered as quasi-steady and consequently the results of this experimental study could be compared with the results of the steady-state experiments to obtain the final flow transition criteria for the agitated regime. A correlation for the axial extent of the agitated flow regime was developed. This correlation

$$
\mathrm{L} / \mathrm{D}=595 \sqrt{\mathrm{Ca}}\left[1-\frac{\alpha_{\mathrm{J}}}{0.854}\right]^{2.25}
$$

shows marked dependence of the axial extent on the void fraction at the CHF location. It is noted that the above correlation is functionally similar to the correlation developed by Ishii and Denten[30] with difference in the exponent. It also shows that the extent of the predispersed region is shorter in the propagating rewetting front case than in the steady state case. This is caused by the increased disturbances generated by the rewetting process. This is a significant effect which has not been known before. This correlation is to be used for the development of heat transfer model for the post-CHF region based on the hydrodynamics of the flow field. It is very important to distinguish between the agitated regime and the dispersed droplet/ligament regime in developing heat transfer model because the heat transfer mechanisms are completely different. 


\section{ACKNOWLEDGEMENTS}

This research was supported by the Westinghouse Savannah River Site through the Department of Energy - Office of Energy Research - Nuclear Engineering Research Grant Program. The authors would like to express their sincere appreciations to Dr. Courtney Apperson of SRS, Drs. David Woodall and T.J. Dolan of INEL and the staff of DOE and SRS. 


\section{REFERENCES}

1. D. B. Collins, M. Gacesa and C. B. Parsons, "Study of onset of premature heat transfer crisis during hydrodynamic instability in a full scale reactor channel", ASME Paper No. 71-HT-11 (1971).

2. W. H. Lowdermilk, C. D. Lanzo and B. L. Siegel, "Investigation of boiling burnout and flow instability of water flowing in tubes", NACA-TN 4382 (1958).

3. K. Mishima and M. Ishii, "Critical heat flux experiments under low flow conditions in a vertical annulus," NUREG/CD-2647, ANL-82-6 (1982).

4. K. Mishima and M. Ishii, "Experimental study on natural convection boiling burnout in an annulus," Proc. Intl. Heat Transfer Conf., Vol. 4 pp. 309-314, Munich (1982).

5. K. Mishima, "Boiling burnout at low flow rate and low pressure conditions," Ph.D. Thesis, Kyoto University, Research Reactor Institute (1984).

6. S. W. Webb and J. C. Chen, " A two-region vapor generation rate model for convective film boiling", Intl. Workshop on Fundamental Aspects of Post Dryout Heat Transfer, Salt Lake City, Utah, April 1-4, NUREG/CR-0060 (1984).

7. N. T. Obot and M. Ishii, "Two-phase flow regime transition criteria in post-dryout region based on flow visualization," Intl. J. Heat Mass Transfer, 31, 2559-2570 (1988).

8. J. G. Denten and M. Ishii, "Flow visualization study of post critical heat flux region for inverted bubbly, slug and annular flow regimes," NUREG/CR-5171, ANL-88-27 (1988).

9. D. A. Barnard, F. R. Dell and R. A. Stinchcombe, "Dryout at low mass velocity for an upward boiling flow of refrigerant 113 in a vertical tube," AERE-R7726 (1973).

10. P. Griffith, C. T. Avedisian and J. P. Walkush, " Counterflow critical heat flux", AICHE Symposium series, No. 174, vol. 74, 149 (1980).

11. G. F. Hewitt, H. A. Kearsey, P. M. C. Lacey and D. J. Pulling, "Burnout and nucleation in climbing film flow", Int. J. Heat Mass Transfer, 8, 793 (1965).

12. J. A. Boure, A. E. Bergles and L. S. Tong, "Review of two-phase flow instability", ASME Paper No. 71-HT-42 (1971).

13. M. Ishii, "Study of flow instabilities in two-phase mixtures," ANL-76-23 (1976).

14. M. Ishii and H. Fauske, "Boiling and dryout behavior in a liquid metal fast breeder reactor subassembly bundle under low heat flux and low flow conditions," Nucl. Sci. Eng., 84, 131-146 (1983). 
15. M. Ledinegg, "Instability of flow during natural and forced convection", Die Warme, 61, 891-898 (1938), Translation USAEC- $t 5-1861$.

16. S. Lele, "Stability analysis of downflow for Westinghouse Savannah River Site reactor", M.S. Thesis, Purdue Univerity, School of Nuclear Engineering, (under preparation), (1992).

17. M. Ishii and I. Kataoka, "Scaling laws for thermalhydraulic system under single-phase and two-phase natural circulation," Nucl. Eng. Design., 81, 41-425 (1984).

18. G. Kocamustafaogullari and M. Ishii, "Scaling of two-phase flow transient using reduced pressure system and simulant Fluid," Nucl. Eng. Design., 104, 121-132 (1987).

19. D.P. Jordan, "Film transition boiling", Adv. Heat Transfer 5, 55-128(1968).

20. L.D. Clemments and C.P. Clover, "Natural convection film boiling heat transfer", Ind. Eng. Chem. 62(9), 26-46 (1970).

21. E.K. Kalinin, I.I. Berlin and V.V. Kostyuk, "Film boiling heat transfer", Adv. Heat Transfer 11, 51-197 (1975).

22. W.F. Laverty and W.M. Rohsenow, "Film boiling of saturated nitrogen flowing in a vertical tube", ASME J. Heat Transfer 89, 90-98 (1967).

23. R.P. Forslund and W.M. Rohsenow, "Dispersed flow film boiling", ASME J. Heat Transfer 90, 399-407 (1968).

24. M. Ishii and G. De Jarlais, "Flow regime transition and interfacial characteristics of inverted annular flow", Nucl. Eng. Des. 95, 171-184 (1986).

25. M. Ishii and G. De Jarlais, "Flow visualization study of inverted annular flow of post dryout heat transfer region", Nucl. Eng. Des. 99, 171-184 (1986).

26. I. Vojtek, "Investigation of dispersed flow heat transfer using different computer codes and heat transfer correlation", Pro. 1st Int. Workshop on Fundamental Aspects of Postdryout Heat Transfer, NUREG/CP-0060, Salt Lake City, Utah, 2-4 April (1984).

27. D.C. Groeneveld, "Inverted annular and low quality film boiling: a state-of-the-art report", Keynote Paper, Pro. 1st Int. Workshop on Fundamental Aspects of Post-dryout Heat Transfer, NUREG/CP-0060, Salt Lake City, Utah, 2-4 April (1984).

28. J.C. Chen, "Review of post-dry out heat transfer in dispersed two-phase flow", Keynote Paper, Pro. 1st Int. Workshop on Fundamental Aspects of Post-dryout Heat Transfer, NUREG/CP-0060, Salt Lake City, Utah, 2-4 April (1984).

29. G. Yadigaroglu and A. Bensalem, "Interfacial mass generation rate modeling in nonequilibrium two-phase flow", Pro. 1st Int. Workshop on Fundamental Aspects of Post- 
dryout Heat Transfer, NUREG/CP-0060, Salt Lake City, Utah, 2-4 April (1984).

30. R. Nelson and C. Unal, "A phenomenological model of the thermal hydraulics of convective boiling during the quenching of hot rod bundles, Part I: Thermal Hydraulics Model," Los Alamos National Laboratory Report LA-UR-91-209, 1991.

31. M. Ishii and J.P. Denten, "Two-phase flow characteristic of inverted bubbly, slug and annular flow in post-critical heat flux region", Nucl. Eng. Des. 121, 349-366 (1990).

32. G. De Jarlais and M. Ishii, "Inverted annular flow experimental study", Argonne National Laboratory Report ANL-85-31, NUREG/CR-4277 (1985).

33. I. Babelli, "Flow visualization study of post-critical heat flux in inverted flow", M.S. Thesis, Purdue Univerity, School of Nuclear Engineering, (under preparation), (1992).

34. I. Babelli, S. T. Revankar and M. Ishii, "Flow visualization study of post-critical heat flux in inverted flow", Accepted for presentation and publication in The Proc. 5th International Topical Meeting on Reactor Thermal-Hydraulics, Sept., 21-23, Salt Lake city, Utah (1992). 

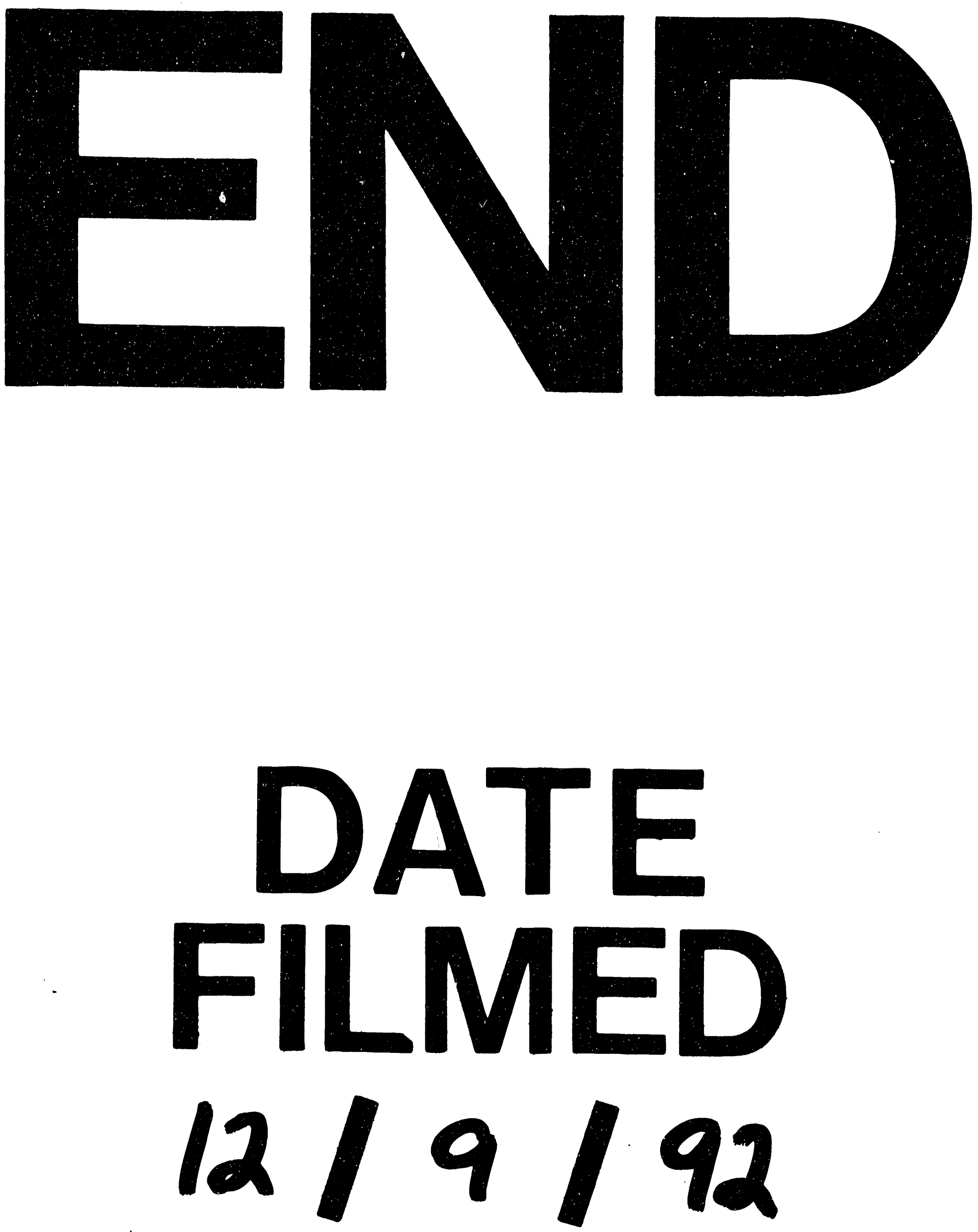
